
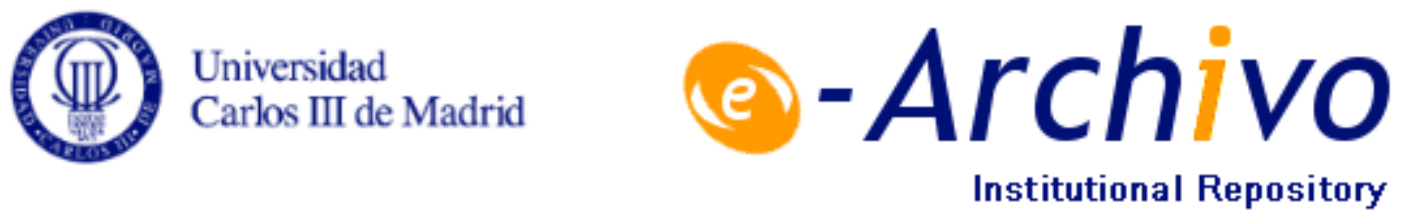

This is a postprint version of the following published document:

Dustmann, C., Fasani, F., Frattini, T., Minale, L. and Schönberg, U. (2017), On the economics and politics of refugee migration. Economic policy, v. 32, n. 91, pp. 497-550. Available in : https://doi.org/10.1093/ epolic/eix008

(C) Oxford University Press 


\section{On the economics and politics of refugee migration}

\section{Christian Dustmann, Francesco Fasani, Tommaso Frattini, Luigi Minale and Uta Schönberg*}

UCL and CReAM; QMUL, CReAM and CEPR; University of Milan, LdA and CReAM; Universidad Carlos III de Madrid, CReAM and IZA; UCL, CReAM, and IAB

\section{SUMMARY}

This paper provides a comprehensive analysis of refugee migration, with emphasis on the current refugee crisis. After first reviewing the institutional framework laid out by the Geneva Convention for Refugees, we demonstrate that, despite numerous at tempts at developing a common European asylum policy, EU countries continue to differ widely in interpretation and implementation. We then describe key features of the current refugee crisis and document the overall magnitudes and types of refugee movements, illegal border crossings and asylum applications to EU Member States. We next study the labour market integration of past refugee migrants to EU countries and draw conclusions for the current situation. Finally, we turn to the economics of refugee migrations, contrasting economic and refugee migrants, discussing the trade offs between long term asylum and temporary protection and highlighting the benefits of well coordinated national asylum policies. We conclude with several policy recommendations.

fEL codes: F22, $\mathcal{7} 15, \mathfrak{J} 61$

\section{INTRODUCTION}

For the first time since the large refugee movements of the 1990s, which followed the breakup of the bipolar order that had dominated Europe since the 1950s, a refugee crisis tops European policy debate. The earlier crisis resulted from the political restructuring of South-Eastern Europe after the Balkan wars and the dissolution of Yugoslavia, which had displaced about 2,700,000 people by the end of 1995, over 700,000 of whom sought asylum in EU Member States (see UNHCR, 2000). The current movements are due primarily to the events that followed the 2001 bombings of New York's twin towers and the uprising in the Middle East commonly known as the 'Arab Spring'. In 2015

* This paper was prepared for presentation at the 64th Panel Meeting of Economic Policy in October 2016. Luigi Minale gratefully acknowledges support from the Ministerio de Economía y Competitividad (Spain, Maria de Maeztu Grant) and Comunidad de Madrid (MadEco CM S2015/ HUM 3444). Christian Dustmann acknowledges funding through the Norface WSF Programme and the DFG (DU1024/1 1) ERC Advanced Grant 323992 DMEA. 
alone, Europe received a total of 1.5 million asylum applications, an unprecedented high that is almost double the previous 1992 peak of 850,000.

At least three features distinguish the present refugee crisis from that in the early 1990s: first, the refugee movements of the early 1990s happened in the aftermath of decades of cold war, a dark era from which an optimistic Europe emerged eager to embrace new economic opportunities and European integration and enlargement. The current crisis, in contrast, falls upon an enlarged Europe, still entangled in the aftershocks of a deep recession, riddled by populist and separatist national movements and challenged by deeply divergent views about how to address this humanitarian crisis. Second, whereas the Balkan wars were considered mainly a Western responsibility and Western resolve finally helped to restore stability, the current crisis involves a multitude of actors and geo-political interests over which Western nations have limited power. And third, the refugees who are currently heading towards Europe are perceived to be culturally more distinct and greater in number than those in the early 1990s.

As a result of these differences, the current crisis is characterized by at least three political challenges: First, and most important, European nations can only marginally influence the primary causes of the conflicts inducing current refugee flows. There is thus no clear indication of when such flows might abate, and no clear time frame for when those who have fled the conflict can be resettled, if at all. Such a lack of predictability creates uncertainty and concern among the populations in the receiving countries, whose fears are easily exploitable by populist movements. Second, the dire economic situations in which many European countries find themselves, coupled with the different views about humanitarian responsibilities, impede political progress and solutions. Last, the lack of a clear legal framework; the unsuitability of past regulations, which have led to confusing ad hoc exceptions; the differences in implementation and interpretation of the underlying Geneva Convention for Refugees (GCR) across European countries; and the challenges that the current crisis poses for the Schengen Agreement have led to a situation in which political progress is proving extremely difficult.

In this paper, we provide background and shed new light on the complexities of the refugee crisis Europe faces. We first answer the question 'who is a refugee?' (Section 2). We start from the definition laid out in the 1951 GCR and emphasize the tremendous heterogeneity in how different European countries interpret and implement it. We argue that this diversity in GCR interpretation and implementation is one important reason for the current lack of political progress that we are witnessing. We then identify the major source areas of the current crisis and resulting migrations (Section 3) by documenting the sharp increases in asylum applications to EU Member States from 2009 onwards, and its unequal distribution across EU Member States.

In Section 4, we use data from the 2008 wave of the EU Labour Force Survey to profile the economic integration of past refugee migrants to EU countries. In particular, we show that migrants who arrived for humanitarian reasons were less likely to be employed than economic migrants from the same origin areas despite similar levels of education. This evidence from past refugee movements underscores the particular 
challenges to host countries and indicates the need for more proactive policies to prevent the poor economic outcomes of refugees.

We then examine the economics of refugee migrations by first contrasting refugee migration with economic migration (Section 5). We argue that whereas the latter is a choice for all parties involved, refugee migrants are forced to leave their home country because of threats to their own lives or those of their family, and countries that receive refugees do so for humanitarian not economic reasons. Further, host countries tend not to have economic integration of the refugee migrants as their primary objective. Receiving countries can decide whether to reject asylum claims, grant full GCR refugee status (which often leads to permanent settlement in the host country), or offer temporary forms of humanitarian support. These different options, by creating different degrees of permanence for individual refugees, greatly affect their incentives to integrate socially and contribute economically. We suggest that clear rules and support mechanisms are needed early on in the migration history, together with fast processing times, fast access to the labour market and active integration programmes. We conclude Section 5 by highlighting the economic advantages of increased coordination in the asylum process across countries; for instance, at the EU level. Such increased coordination would reduce the free-rider problem inherent in the provision of (the public good of) refugee status, minimize the costs of providing asylum to a given number of refugees and alleviate countries' incentives to implement policies aimed at deterring asylum applications, which may harm refugee integration.

We finally discuss the implications of earlier evidence for optimal and feasible refugee

policies that Europe should implement not simply to address the current crisis but also to deal with future migration developments.

\section{WHO IS A REFUGEE?}

\subsection{The international framework}

Modern refugee legislation has its origins in the aftermath of World War II and in the refugee crises of the preceding interwar years. Grounded in Article 14 of the 1948 Universal Declaration of Human Rights, which recognizes the right of persons to seek asylum from persecution in other countries, the United Nations Geneva Convention relating to the Status of Refugees (GCR) was adopted in 1951. In its first article, the convention defines the refugee as follows:

[amy person who] owing to a well founded fear of being persecuted for reasons of race, religion, na tionality, membership of a particular social group or political opinion, is outside the country of his nationality and is unable or, owing to such fear, is unwilling to avail himself of the protection of that country; or who, not having a nationality and being outside the country of his former ha bitual residence as a result of such events, is unable or, owing to such fear, is unwilling to return to it. 
The GCR not only broadly defines the rights of refugees and the obligations of hosting states, but establishes the principle of non refoulement (Article 33), which prevents host countries from returning refugees against their will to any territory in which they fear a threat to life or freedom. ${ }^{1}$ Although the convention was originally limited to persons fleeing events occurring within Europe and before 1 January 1951, the 1967 Protocol removed these limitations and endowed the GCR with universal coverage. As of April 2015, 145 states have signed the 1951 Convention and 142 have signed both the Convention and the 1967 Protocol.

Being the only global legal instruments that explicitly regulate refugee rights, the 1951 Convention and the 1967 Protocol still define the international framework regulating asylum policy. Nevertheless, being based on the concept of individual persecution, the GCR definition of refugees does not specifically address the more general issue of civilians fleeing wars and conflicts. The United Nations High Commissioner for Refugees (UNHCR), however, considers that persons fleeing the civil wars and ethnic, tribal and religious violence and whose country of origin is unwilling or unable to protect them should be considered refugees even if they are fleeing a general rather than an individual threat. Hence, some regional human rights treaties have since expanded the GCR definition to include these people. ${ }^{2}$ On the other hand, some countries, particularly in Western Europe, argue that civilians fleeing conflicts should not be granted full refugee status. As a result, they have developed different forms of temporary/subsidiary humanitarian protection for these people. These alternative hosting schemes have been used in Europe to respond to sudden and massive influxes of war-displaced individuals (e.g. from the 1990s conflicts in the former Yugoslavia and Kosovo). In these cases, each civilian belonging to a certain group is considered a refugee prima facie (i.e. in the absence of evidence to the contrary), eliminating the need for individual status determination. Such group determination permits speedy admittance to safe countries, but with no guarantee of permanent asylum.

At the same time, because the GCR does not stipulate how receiving countries should determine whether an individual meets the criteria for refugee status, each signatory country employs its own procedures for status recognition, with many (especially in the developing world) still lacking any formalized system. ${ }^{3}$ Similarly, although the GCR

1 'No Contracting State shall expel or return ("refouler") a refugee in any manner whatsoever to the frontiers of territories where his life or freedom would be threatened on account of his race, religion, nationality, membership of a particular social group or political opinion' (Geneva Convention, Article 33.1).

2 For instance, the African Union (formerly the Organization of African Unity) adopted the 'Convention Governing the Specific Aspects of Refugee Problems in Africa' in 1969 while the Organization of American States signed the 'Cartagena Declaration on Refugees' in 1984. In both cases, the 1951 GCR definition was expanded to include those compelled to leave their country owing to such threats as external aggression, occupation, foreign domination or generalized violence.

3 Turkey, for instance, did not establish a legal framework for asylum and create an agency responsible for assessing asylum applications until 2013. Syrian refugees, however, are managed outside this system and benefit from a group based temporary protection scheme. 


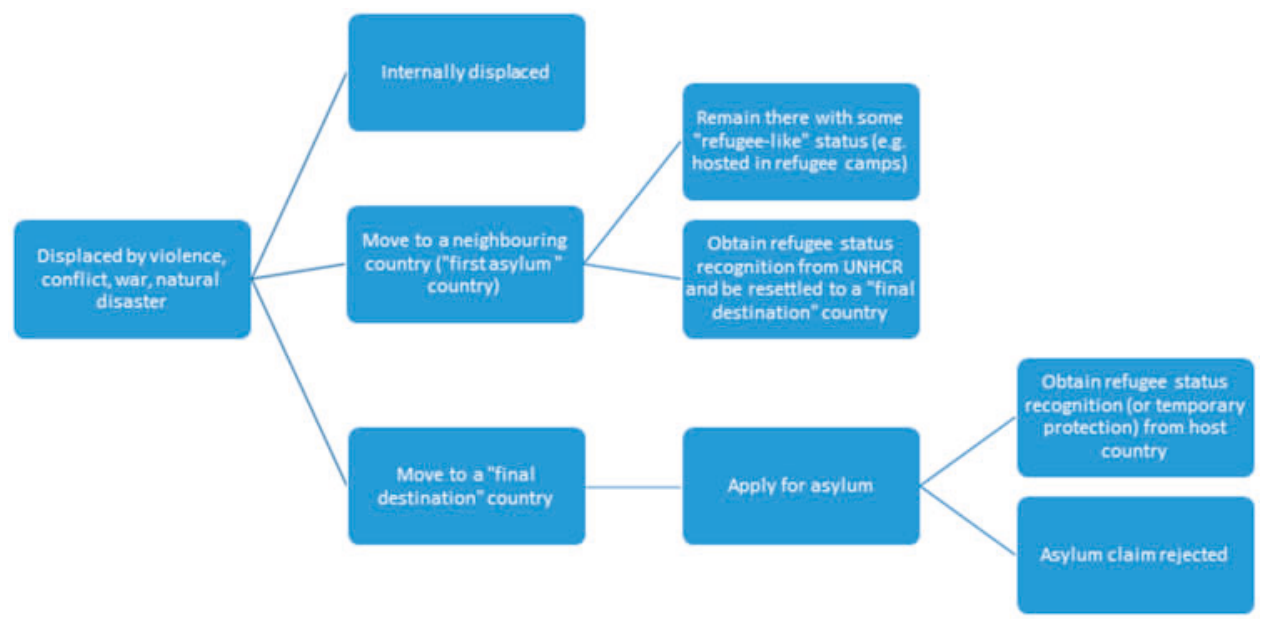

Figure 1. From displacement to refugee status

clearly states the rights and entitlements of refugees access to courts (Article 16), labour market (Articles 17 19), housing (Article 21), public education (Article 22) and so forth it limits the enjoyment of these benefits to 'refugees lawfully staying' in the host country territory (and thus not to current and rejected asylum seekers). It also uses overly broad formulations (e.g. 'treatment as favourable as possible'), which leave much room for host-state interpretation. Not surprisingly, such breadth has resulted in disparities as the different governments adapt their asylum laws to their own resources, refugee migration histories and political and national security concerns (see Section 2.4.).

\subsection{From displacement to refugee status}

In Figure 1, we reconstruct the progression from displacement from region of residence to eventual recognition as a refugee in a third country. Those who flee their homes are technically defined as 'displaced persons', reflecting their displacement by such traumatic events as violence, conflict, or natural disaster, and are classified by the UNHCR as their 'population of concern'. These individuals may be divided into those who are 'internally displaced' (IDPs) that is, forced to leave their homes but still residing in the country of origin and those who have moved to a third country. These latter can be further divided into those who have moved to a neighbouring country ('first asylum country') and those who have managed (either legally or illegally) to reach a country that accepts asylum applications and offers GCR refugee status or other forms of humanitarian protection ('final destination' country). Obviously, these three outcomes can also represent consecutive steps in the same process.

In general, displaced persons in neighbouring countries are hosted in refugee camps but, not being subject to a formal status determination process, do not usually have recognized refugee status. UNHCR defines these individuals as being in a 'refugee-like' situation, as belonging to 'groups of persons who are outside their country or territory of 
origin and who face protection risks similar to those of refugees, but for whom refugee status has, for practical or other reasons, not been ascertained' (UNHCR, 2015a). In fact, 'first asylum' countries receiving inflows of displaced persons are often developing countries that do not and usually cannot afford to have any formal system in place to manage and assess asylum applications. Displaced people in refugee camps are thus often subsidized by UNHCR, non-governmental organizations (NGOs), and international aid and can remain in that situation for years. For these persons, UNHCR operates 'resettlement schemes' that transfer refugees from one host country to another that has agreed to admit them and ultimately grant them permanent settlement. Candidates for resettlement undergo a formal refugee status determination process while still in the origin or first asylum country, after which successful candidates are relocated to the destination countries. A major advantage of the resettlement schemes is that displaced people do not need to engage in dangerous and illegal trips to find a safe haven abroad. Currently, however, only a relatively small number of states participate in the UNHCR resettlement programme, with the United States being the world's top resettlement country, followed by Australia, Canada, New Zealand and the Scandinavian countries.

Only a relatively small fraction of the total displaced population manages to reach a country that has a formal system of refugee status recognition (see also Hatton, 2009). These arrivals are usually unauthorized border crossings using forged documents and/ or the help of smugglers. Once arrived in the host country, displaced persons have the right to apply for asylum and reside in the host country until a decision is made. The process outcome can either be recognition of full Geneva refugee status, the offer of some form of temporary humanitarian protection, or a rejection. Rejected asylum seekers have to either leave the host country autonomously or be returned to their home country. For many, however, the principle of non refoulement applies, preventing the host country from expelling these individuals but leaving them with an undefined status (which often leads to undocumented residency). In general, return to the home country, although not represented in Figure 1, is an option at all stages of the process.

In its own records, UNHCR counts as refugees all individuals residing in a third country who are in a refugee-like situation, who enjoy formally recognized refugee status (under the GCR, 1967 Protocol, or any of the regional conventions on asylum), or who have been granted complementary and temporary forms of protection (UNHCR, 2015a). Hence, throughout the remainder of the paper, we adopt their broad definition of refugees but distinguish individuals with refugee-like status from those with recognized refugee status whenever needed.

\subsection{Displaced population, refugees and asylum seekers: evidence from UNHCR data}

Table 1 provides an overview of the worldwide population of displaced individuals. The table shows that, as of 2015, most of the almost 59 million displaced individuals worldwide were still residing within the borders of their home countries; only $30.7 \%$ 
Table 1. Origin and destination of UNHGR's population of concern (year 2015)

\begin{tabular}{lccccc}
\hline \hline & \multicolumn{4}{c}{ Continent of origin } \\
\cline { 2 - 5 } & Africa & Asia & Europe & South America & World \\
\hline UNHCR population of concern (thous.) & 19,124 & 29,423 & 2,672 & 7,765 & 58,991 \\
Refugees (thous.) & 6,050 & 10,753 & 686 & 625 & 18,122 \\
$\quad$ of which are asylum seekers (thous.) & 659 & 1,146 & 179 & 177 & 2,162 \\
Share of refugees & 0.316 & 0.365 & 0.257 & 0.080 & 0.307 \\
\hline Refugees distribution across destinations & & & & & 0.289 \\
Africa & 0.819 & 0.026 & 0.000 & 0.000 & 0.501 \\
Asia & 0.056 & 0.813 & 0.003 & 0.000 & 0.147 \\
Europe & 0.101 & 0.129 & 0.937 & 0.028 & 0.039 \\
North America & 0.019 & 0.025 & 0.057 & 0.430 & 0.004 \\
Oceania & 0.001 & 0.005 & 0.001 & 0.000 & 0.020 \\
South America & 0.003 & 0.001 & 0.001 & 0.541 & 1 \\
Total & 1 & 1 & 1 & 1 & 1 \\
\hline \hline
\end{tabular}

Notes: The table reports, separately for each continent of origin and for the World as a whole, the stock of the overall UNCHR's population of concern (row 1), the stock of refugees (including asylum seekers, row 2) and the stock of asylum seekers (row 3). All figures are expressed in thousand. Row 4 reports the share of refugees (includ ing asylum seekers) out of the total UNHCR population of concern. The bottom rows report the distribution of refugees (including asylum seekers) from each continent of origin across continents of destination.

Source: Own calculations based on UNCHR data.

had left their country to become refugees abroad. For European (2.7 million) and South American (7.8 million) displaced persons, this share is 25.7 and 8\%, respectively, but for the 19 million Africans and 29 million Asians displaced by conflict or violence, it reaches 31.6 and $36.5 \%$, respectively. It is also worth noting that, as the bottom panel of Table 1 shows, most of these international movements involve neighbouring countries located on the same continent. For instance, in 2015, almost $82 \%$ of African refugees were residing in another African country, while the corresponding values for Asian, European and South American refugees were 81, 94 and 54\%, respectively. Europe as a whole was, in 2015, hosting $15 \%$ of the world's refugees.

Figure 2 plots the time series of world refugee population (in millions) by continent of origin. The stock of refugees has been large over the entire 19802015 period. Nevertheless, large differences exist between continents, with refugee populations originating mostly from Asia and Africa dwarfing refugee populations from South America and Europe, including those induced by the Balkan wars. The figure also illustrates two notable peaks in the total refugee population, one in the early 1990s and the other in the 2010s, with a further rapid surge in the most recent years. The first peak, when the total refugee population reached 15 million people, was related to the Balkan wars and to conflicts in Africa (Rwanda, Somalia) and Asia (Iraq, Afghanistan). The second peak, starting around 2008, corresponds to the conflicts in Afghanistan and Iraq, and to the consequences of the Arab Spring uprisings in North Africa. The 20142015 surge is mostly explained by the Syrian civil war. The graph further shows that in 2015, Asian citizens accounted for more than 9.5 million refugees and African refugees for over 5 


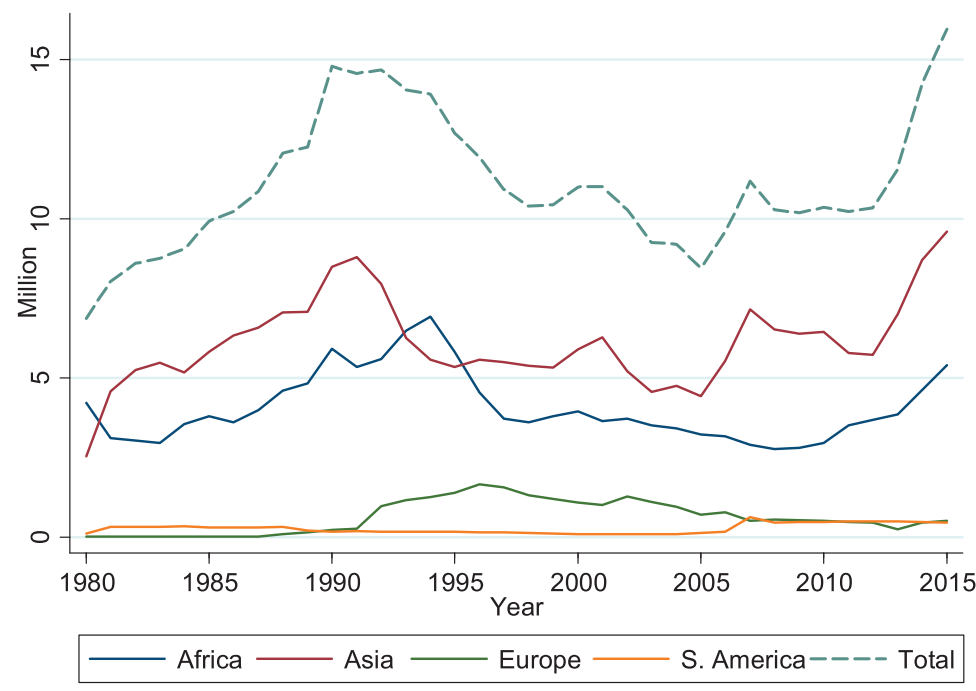

Figure 2. Evolution of refugee populations by origin continent (1980-2015)

Note: The figure reports the evolution of the stock of refugees (in millions) by continent of origin, and overall, be tween 1980 and 2015.

Source: Authors' calculations based on UNHCR data.

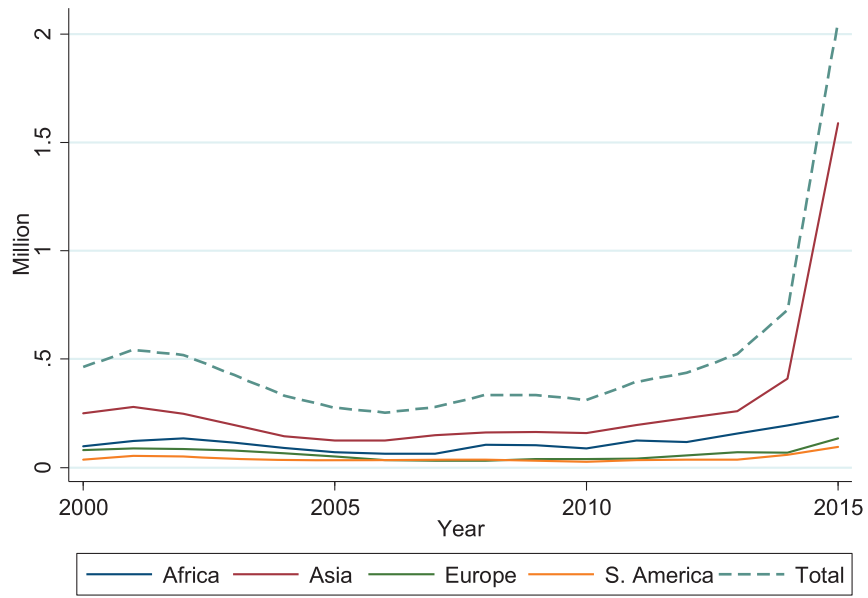

Figure 3. Annual number of asylum applications by origin continent (2000-2015)

Note: The figure reports the annual number of asylum applications (in millions) by continent of origin, and overall, between 2000 and 2015.

Source: Authors' calculations based on UNHCR data.

million, with the remaining million equally split between European and South American refugees.

In Figure 3, we report the total number of asylum applications (in millions) worldwide in each year between 2000 and 2015, distinguishing again by continent of origin. From a global figure of over 0.5 million asylum applications per year in the 2001 2002, this 
Table 2. Different stages of the process of becoming a refugee: the case of Syrians

\begin{tabular}{|c|c|c|c|c|c|}
\hline & & & & Millions & $\%$ \\
\hline \multicolumn{4}{|c|}{ Total population (pre conflict) } & 21.96 & \\
\hline \multicolumn{4}{|c|}{ Not displaced } & 10.10 & 46.0 \\
\hline Displaced & & & & 11.86 & 54.0 \\
\hline \multirow[t]{15}{*}{ of which: } & \multirow{3}{*}{\multicolumn{3}{|c|}{$\begin{array}{l}\text { Internally displaced } \\
\text { Offered Resettlement (as of April 2016) } \\
\text { Refugees/Asylum seekers at } 31 \text { December 2015: }\end{array}$}} & 6.56 & 55.3 \\
\hline & & & & 0.18 & 1.5 \\
\hline & & & & 5.12 & 43.2 \\
\hline & \multirow[t]{12}{*}{ of which: } & \multicolumn{2}{|c|}{$\begin{array}{l}\text { in Neighbouring countries } \\
\text { (as of 31December 2015): }\end{array}$} & 4.56 & 89.0 \\
\hline & & \multirow{5}{*}{ of which: } & Turkey & 2.50 & 54.9 \\
\hline & & & Lebanon & 1.06 & 23.3 \\
\hline & & & Jordan & 0.63 & 13.8 \\
\hline & & & Iraq & 0.24 & 5.4 \\
\hline & & & Egypt & 0.12 & 2.6 \\
\hline & & \multicolumn{2}{|c|}{ in $\mathrm{EU} 28+\mathrm{NOR}+\mathrm{CH}$} & 0.49 & 9.6 \\
\hline & & \multirow[t]{5}{*}{ of which: } & Germany & 0.20 & 40.8 \\
\hline & & & Sweden & 0.10 & 20.8 \\
\hline & & & Austria & 0.03 & 6.8 \\
\hline & & & Netherlands & 0.03 & 6.5 \\
\hline & & & Hungary & 0.02 & 3.9 \\
\hline
\end{tabular}

Notes: The table reports the total Syrian population, the number of internally displaced Syrians, the number of Syrian citizens offered Resettlement to a safe host country (the figure includes both confirmed pledges and indi viduals actually resettled) and those hosted in the EU and in neighbouring countries (including both asylum seekers and individuals with recognized refugee status).

Source: Own calculations based on UNHCR Population Statistics data.

number declined to approximately 0.3 million per year between 2004 and 2010 and then began increasing sharply. In 2015, more than 2 million asylum applications were filed worldwide, a clearly unprecedented number given the just over 850,000 that made up the 1992 peak (Hatton, 2016). In 2015, the majority of asylum seekers originated from Asia (due especially to Syrian and Afghan asylum seekers), which accounted for almost 1.6 million applications.

In Table 2, we draw on the latest available UNHCR figures, updated to December 2015, to show the estimated number of Syrian citizens at different stages of the process that goes from displacement to being recognized as refugee. Of a total population of almost 22 million people (in 2011), almost 12 million of Syrian citizens (54\%) are currently displaced by the conflict. Slightly more than half of them (6.6 million) are still in Syria, being IDP. Just 1.5\% (180 thousand) have been offered resettlement or resettled to a safe host country. The remaining 43.2\% (5.1 million) have autonomously reached a third country. The vast majority of this latter group (89\%; 4.6 million) is hosted under a refugee-like status in a neighbouring country: 2.5 million in Turkey, 1 million in Lebanon, 
630 thousand in Jordan, 240 thousand in Iraq and 120 thousand in Egypt. About half a million Syrians have reached an EU country and were granted asylum or are waiting for their asylum claim to processed: 40\% of them are hosted in Germany (200 thousand), followed by Sweden (100), Austria (30), the Netherlands (30) and Hungary (20).

As for the case of Syrian citizens, UNHCR resettlement schemes still account for a relatively minor fraction of the refugee flows. The UNHCR estimated that over 1.1 million of refugees are globally in need of resettlement in 2016 (UNHCR, 2015b). The latest records show that 26 countries admitted a total of 105,200 resettled refugees in 2014, leading to a total of 900 thousand resettlements over the last decade (UNHCR, 2015a). The United States are by far the major recipient of resettled refugees. In 2014, United States admitted 73 thousand refugees (70\% of the total), followed by Canada $(12 \%)$, Australia (11\%), Sweden (2\%), Norway and Finland (1\% each).

\subsection{Asylum policy in Europe}

2.4.1. Towards a common European policy. In the late 1980s and early 1990s, the gradual fall of the Iron Curtain triggered massive across-state movements that particularly affected Western European countries. The collapse of former Yugoslavia and the conflicts that tore apart the region for almost a decade generated additional flows of people seeking asylum. These large refugee inflows across Europe created a need to rethink asylum policies in all European countries. They also generated a shift towards a higher degree of coordination at the EU level. For example, since the 1990 adoption of the Dublin Convention, the EU has tried to develop a common European asylum system with the principal aim of clarifying which receiving country is responsible for asylum claims and preventing multiple application submissions in Member States. The convention itself, which came into force in 1997 1998, established the principle that the Member State through which the asylum seeker first entered the EU is responsible for assessing the asylum claim. To ensure effective application of the convention, in 2000, the EU approved the EURODAG Regulation, which established a common asylum fingerprint database. Between 1999 and 2005, several additional legislative measures were implemented to harmonize common minimum standards for asylum. In 2000, for instance, the European Refugee Fund (ERF) was created to share the costs of reception, integration and voluntary repatriation of people in need of international protection. The ERF was endowed with €630 million over the period 20082013 (105 million per year). In 2014, the ERF was replaced by the Asylum, Migration and Integration Fund (AMIF), which has a budget of $€ 3.137$ billion for the seven years 20142020 , or $€ 448$ million per year. ${ }^{4}$ It is worth noting, that the resources targeted to these funds are

4 http://ec.europa.eu/dgs/home affairs/financing/fundings/migration asylum borders/index en.htm, accessed on 10 February 2017. 
relatively small when compared to other EU funds. For instance, the European Social Fund (ESF) receives a funding of $€ 10$ billion a year, ${ }^{5}$ and the European Agricultural Fund for Rural Development (EAFRD) has been endowed with $€ 100$ billion over the seven years 20142020 , or $€ 14.2$ billion per year. ${ }^{6}$

Yet despite these persistent attempts to establish a single and harmonized European asylum policy, individual Member States have de facto maintained full sovereignty over the implementation of their national asylum policies. In addition, as highlighted by the current refugee crisis, the European common policy on asylum is riddled with weaknesses. One notable example is the so-called EU 'refugee relocation system' based on a September 2015 EU agreement to relocate 160 thousand refugees from Italy and Greece to other European countries over a period of two years. Because several countries voted against the scheme and refused to participate, as of 15 September 2016, only $9 \%(14,478)$ of the promised 160,000 places have been made available by some of the participating countries and less than 5\% (4,890) of the refugees have actually been relocated. ${ }^{7}$

2.4.2. Heterogeneity in asylum policies across Europe. The different exposures to refugee inflows (see Section 3.3.) and the lack of an effective European-level mechanism to 'spread the burden' of hosting refugee populations, led many countries to implement procedures aimed at reducing inflows into their territories. One such strategy is to tighten visa requirements and border enforcement to reduce the number of asylum seekers that manage to reach the territory and apply for refugee status. Another is to vary the efficiency of application assessment and/or become stricter about granting protection to applicants. Governments can also decide whether to grant full GCR refugee status or to offer subsidiary forms of humanitarian protection. They can also greatly impact the treatment given to asylum seekers and refugees by regulating and limiting their access to such advantages as benefit entitlements, the labour market and choice of residence. In this section, we document this heterogeneity using both UNHCR data and a summary of national legislative differences.

UNHCR data (see Data Appendix A.1) permit the construction of informative indicators of the efficiency and 'generosity' of national asylum policies. First, because governments may try to discourage potential refugees by under-investing in the staff and resources for screening thereby prolonging wait times and increasing outcome uncertainty we use share of applications evaluated over total submitted each year to compare the speed and efficiency of application processing in different countries. We illustrate the pace of processing applications in Figure 4, whose vertical axis reports

5 http://ec.europa.eu/esf/main.jsp?catId 35\&langId en, accessed on 10 February 2017.

6 http://ec.europa.eu/agriculture/rural development 2014 2020/index en.htm, accessed on 10 February 2017.

7 http://ec.europa.eu/dgs/home affairs/what we do/policies/european agenda migration/press mate $\mathrm{rial} / \mathrm{docs} / \mathrm{state}$ of play relocation en.pdf, accessed on 19 September 2016. 


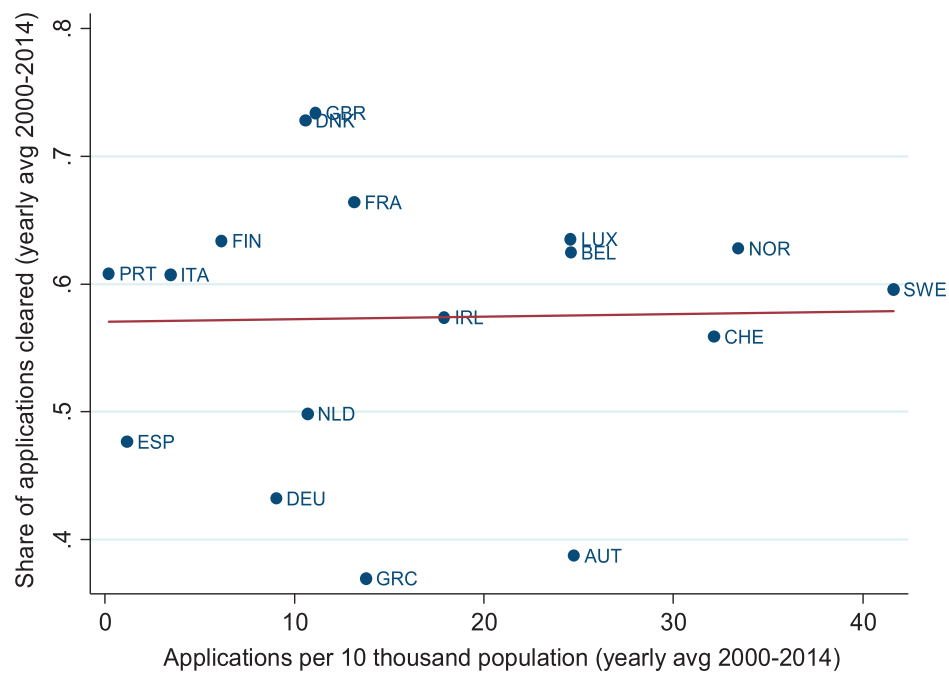

Figure 4. Share of asylum applications cleared and applications received in EU15, Norway and Switzerland (yearly averages for 2000-2014)

Note: The table plots the share of applications cleared against the applications received for EU15 countries, Norway and Switzerland. Numbers are yearly averages for the 20002014 period.

Source: Authors' calculations based on UNHCR data.

the yearly average of the application shares processed in EU15 + NOR + CHE countries over the 20002014 period. This share varies from a minimum of $37 \%$ in Greece to a maximum of $73 \%$ in the UK, with an overall average of approximately $57 \%$. These numbers imply that it takes Greece an average of almost 3 years to process all applications received in any given year, while the UK takes less than 1.5 years. The figure also suggests that the pace of application processing is not mechanically determined by the number of applications received (per 10,000 population), which are reported on the horizontal axis. In fact, the numbers of applications processed each year in the three countries that have received the largest inflows of applicants (relative to population) in the last 15 years Sweden, Norway and Switzerland are close to, or even above, the European average. On the contrary, among the three countries that received the smallest inflows, Portugal and Italy have processing times close to the European average (both around $60 \%$ ) while Spain only manages to assess $47 \%$ of its yearly application inflow. While some of the cross-country variations in processing time could be due to differences in the composition of asylum applications, ${ }^{8}$ the absence of a correlation between processing time and number of applications received suggests that countries can choose their own application processing pace and that those receiving larger inflows probably invest more resources in their screening processes.

8 Some countries, for instance, may systematically receive more applications from a group of potential refugees that are inherently harder to evaluate, slowing down the screening process. 


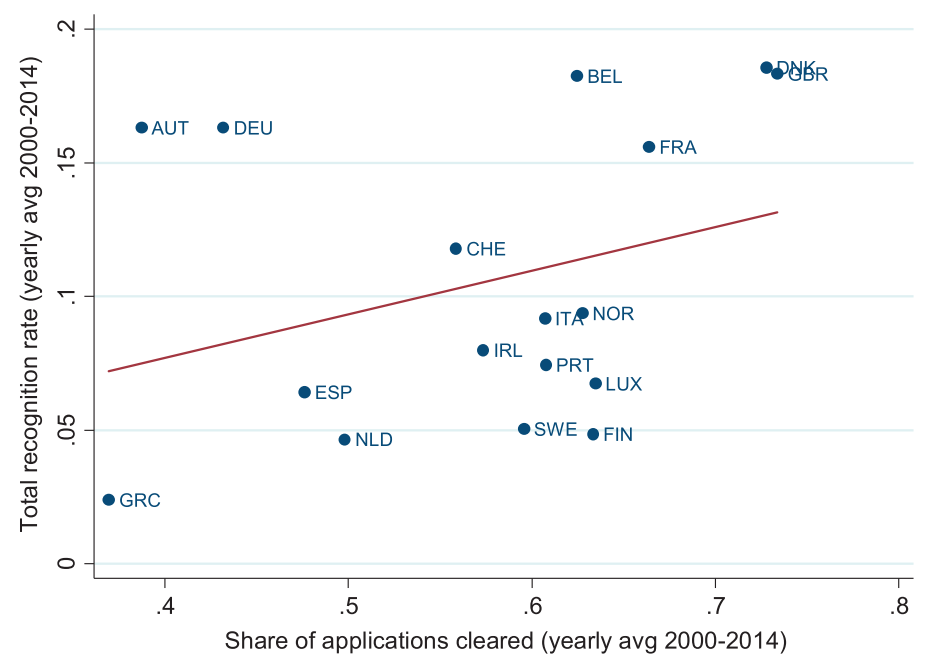

Figure 5. Refugee status recognition rates and share of asylum applications cleared in EU15, Norway and Switzerland (yearly average for 2000-2014)

Note: The figure plots the total recognition rate against the share of applications cleared for EU15 countries, Norway and Switzerland. Numbers refer to yearly averages for the 20002014 period.

Source: Authors' calculations based on UNHCR data.

Figure 5 demonstrates that European countries also differ widely in their asylum generosity, which we measure here as the 'total recognition rate', the number of positive decisions to grant some form of humanitarian protection (GCR refugee status or other subsidiary protection) over the total number of applications processed. On average, only about $10 \%$ of applications submitted in EU15 + NOR + CHE countries between 2000 and 2014 led to recognition of refugee status. This share, however, varies from as little as $2 \%$ in Greece to approximately $18 \%$ in Denmark. Nevertheless, the figure shows a positive correlation (fitted line) between yearly shares of applications processed and recognition rates: countries that are more efficient in screening applications tend also to be more generous in offering refugee status. ${ }^{9}$ This positive slope suggests that European countries that are faster in screening applications are not achieving this target simply by rejecting more applicants. On the contrary, countries like Belgium, France, Denmark and the UK seem to combine a relatively high degree of both efficiency and generosity.

As discussed in Section 2.1., national governments maintain a substantial degree of discretion in deciding upon the exact status to be granted to asylum applicants. Using UNHCR statistical data, we can measure the 'Geneva refugee recognition rate' as the share of applicants accorded full GCR refugee status over the total granted some form of humanitarian protection. Table 3 reports the total number of asylum applications approved by each country in 2014, together with the share of individuals approved for full

9 Austria and Germany appear as outliers in this graph, having relatively high recognition rates but also relatively long processing times. 
Table 3. Total number of approved asylum applications and share with full Geneva refugee status by host country

\begin{tabular}{|c|c|c|c|c|c|c|}
\hline \multirow[t]{2}{*}{ Host country } & \multicolumn{2}{|c|}{ All origin countries } & \multicolumn{2}{|c|}{ Syria } & \multicolumn{2}{|c|}{ Afghanistan } \\
\hline & $\begin{array}{l}\text { refugee } \\
\text { status } \\
\text { granted }\end{array}$ & $\begin{array}{c}\text { share with } \\
\text { full Geneva } \\
\text { status }\end{array}$ & $\begin{array}{l}\text { refugee } \\
\text { status } \\
\text { granted }\end{array}$ & $\begin{array}{c}\text { share with } \\
\text { full Geneva } \\
\text { status }\end{array}$ & $\begin{array}{l}\text { refugee } \\
\text { status } \\
\text { granted }\end{array}$ & $\begin{array}{c}\text { share with } \\
\text { full Geneva } \\
\text { status }\end{array}$ \\
\hline Austria & 11,351 & 0.769 & 3,653 & 0.913 & 1,534 & 0.576 \\
\hline Belgium & 8,479 & 0.810 & 1,705 & 0.740 & 1,269 & 0.638 \\
\hline Bulgaria & 7,000 & 0.737 & 6,406 & 0.753 & 24 & 0.292 \\
\hline Croatia & 26 & 0.615 & & & & \\
\hline Cyprus & 1,243 & 0.073 & 926 & 0.000 & & \\
\hline Czech Rep. & 376 & 0.218 & 71 & 0.000 & & \\
\hline Denmark & 5,670 & 0.689 & 4,002 & 0.782 & 128 & 0.188 \\
\hline Estonia & 20 & 1.000 & & & & \\
\hline Finland & 1,346 & 0.372 & 96 & 0.365 & 119 & 0.202 \\
\hline France & 21,093 & 0.789 & 1,468 & 0.640 & 712 & 0.431 \\
\hline Germany & 40,563 & 0.821 & 23,859 & 0.860 & 3,403 & 0.595 \\
\hline Greece & 3,852 & 0.539 & 718 & 0.735 & 827 & 0.440 \\
\hline Hungary & 476 & 0.504 & 171 & 0.643 & 75 & 0.227 \\
\hline Ireland & 504 & 1.000 & & & & \\
\hline Italy & 20,582 & 0.177 & 313 & 0.732 & 2,398 & 0.106 \\
\hline Latvia & 23 & 0.130 & & & & \\
\hline Lithuania & 91 & 0.264 & & & & \\
\hline Luxembourg & 197 & 0.802 & & & & \\
\hline Malta & 1,478 & 0.158 & 366 & 0.016 & & \\
\hline Netherlands & 13,250 & 0.207 & 5,439 & 0.064 & 415 & 0.439 \\
\hline Norway & 5,076 & 0.754 & 1,294 & 0.444 & 317 & 0.577 \\
\hline Poland & 450 & 0.593 & 132 & 0.871 & & \\
\hline Portugal & 109 & 0.165 & & & & \\
\hline Romania & 753 & 0.503 & 467 & 0.385 & 51 & 0.627 \\
\hline Slovakia & 113 & 0.124 & & & & \\
\hline Slovenia & 44 & 0.773 & & & & \\
\hline Spain & 1,583 & 0.241 & 1,162 & 0.105 & & \\
\hline Sweden & 32,347 & 0.331 & 16,404 & 0.107 & 1,765 & 0.405 \\
\hline Switzerland & 14,123 & 0.439 & 2,821 & 0.325 & 1,855 & 0.156 \\
\hline United Kingdom & 11,874 & 0.906 & 1,423 & 0.976 & 713 & 0.851 \\
\hline $\mathrm{EU} 15+\mathrm{NOR}+\mathrm{CHE}$ & 191,999 & 0.578 & 64,357 & 0.545 & 15,455 & 0.431 \\
\hline $\mathrm{EU} 28+\mathrm{NOR}+\mathrm{CHE}$ & 204,092 & 0.576 & 72,896 & 0.553 & 15,605 & 0.431 \\
\hline
\end{tabular}

Notes: The table reports, for each EU host country, the number of asylum applications approved and the share of applications that were given full refugee status according to the Geneva Convention in 2014 first for all countries of origin, and then separately for Syrians and Afghans. In countries with more than one level in the procedure (first instance, appeal, etc.), the numbers for both procedures have been added up.

Source: 2014 UNHCR Statistical Year Book.

GCR status. In 2014, 204,092 asylum applications were approved in European Economic Area (EEA) countries, the vast majority in a Western European country. Of these, 58\% were given full GCR refugee status, while the others received only subsidiary protection. There is, however, considerable heterogeneity in the frequency of refugee status across countries:, whereas Italy, the Netherlands and Spain, for instance, granted GCR status to less than 25\% of total successful applicants, this share was around $80 \%$ in Austria, Belgium and Germany and $91 \%$ in the UK. These differences, although possibly indicative of different interpretations of the common legal framework, may also be 
due to differences in the type of applications received. For this reason, in columns 34 and 56 of the table, we focus on Syrian and Afghan refugees, respectively. Once again, we observe substantial heterogeneity in the treatment of refugees from the same origin countries, with Syrians more likely to receive full GCR status than Afghans in almost all receiving countries. Nevertheless, even though in countries like the UK (97\%) and Austria (91\%), almost all Syrian refugees are given full Geneva status, this share is as low as $10 \%$ in large destination countries like Sweden. The GCR status recognition rate for Afghan refugees similarly varies from $85 \%$ in the UK to $10 \%$ in Italy.

National asylum policies can also vary along many other dimensions, a few examples of which we summarize in Table 4 at different stages of the process. ${ }^{10}$ National governments can, for example, employ lists of 'safe countries of origin' to accelerate asylum application screening, which in the case of EU Member States means all other Member States (plus Switzerland and Norway) as safe countries of origin. In general, to qualify as a safe third country, a nation must implement the GCR and offer potential refugees the opportunity to apply for asylum. ${ }^{11}$ Yet, only eight EU countries Austria, Belgium, Denmark, Germany, France, Ireland, Luxembourg and the UK have adopted official lists of safe origin countries outside the EU, and even these lists vary widely in both number and countries included. For example, whereas Ireland's list contains only one country (South Africa), the UK's includes 26 countries. Of these, Bosnia and Herzegovina $(\mathrm{BIH})$ and the Former Yugoslav Republic of Macedonia (MKD) are considered safe by all list adopters except Ireland. Albania (ALB) and Montenegro (MNE) are considered safe by all but Germany and Ireland, and Kosovo (RKS) is deemed safe by Austria, Belgium, Denmark, Luxembourg and the UK, but not by France, Germany or Ireland. A related concept, central to the Dublin Convention, is the 'safe third country', a construct used to justify the rejection of applications from asylum seekers who transited through a safe country (where they could have applied for asylum) and subsequent forced return to that country.

All EU countries tend to impose restrictions on asylum seekers' labour market access, a constraint intended to reduce incentives for economic migrants to submit (unfounded) asylum applications. In general, asylum seekers are prevented from being (legally) employed for a minimum period that should theoretically correspond to the time required to process their claims. According to EU Directive 2013/33, Member States must

10 The European Council on Refugees and Exiles (ECRE; http://www.ecre.org/) recently created an Asylum Information Database (AIDA) containing information on asylum procedures, reception con ditions and detention across 16 EU Member States. This database provides a clear picture of the cur rent heterogeneity in policies across these states and is one of the main sources used here.

11 In a highly controversial decision, Norway's parliament agreed in November 2015 to amend the Immigration Act, removing the requirement that a country accept and process asylum applications to be considered a safe third country. This change implies that Russia can be deemed safe to receive asylum seekers and allows Norway to forcedly deport asylum seekers entering through the Artic border with Russia (the 'artic route'). In similar manner, a March 2016 EU agreement with Turkey implies that Greece can consider Turkey a safe country, allowing Greece to transfer asylum seekers from its territory to Turkey's. 


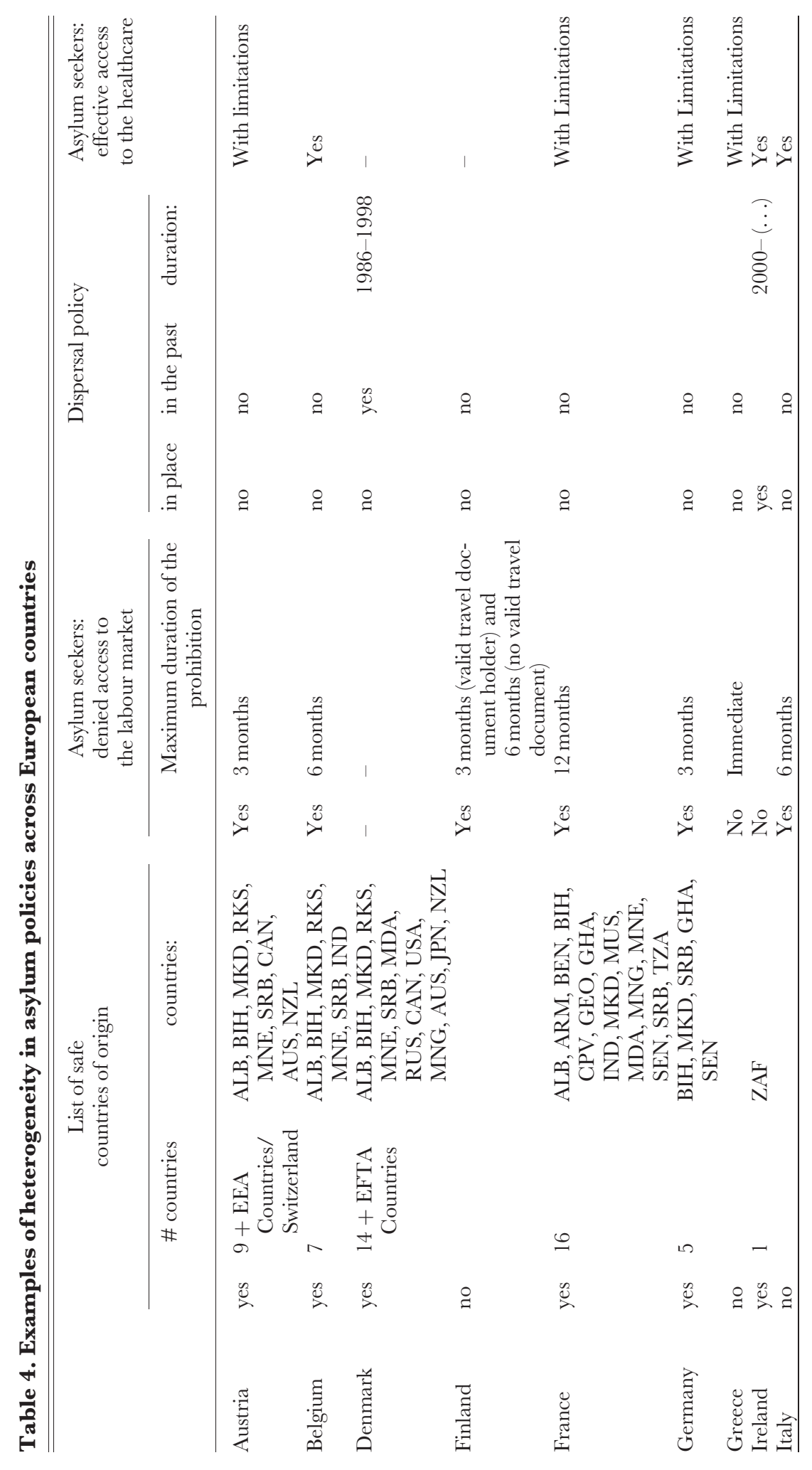




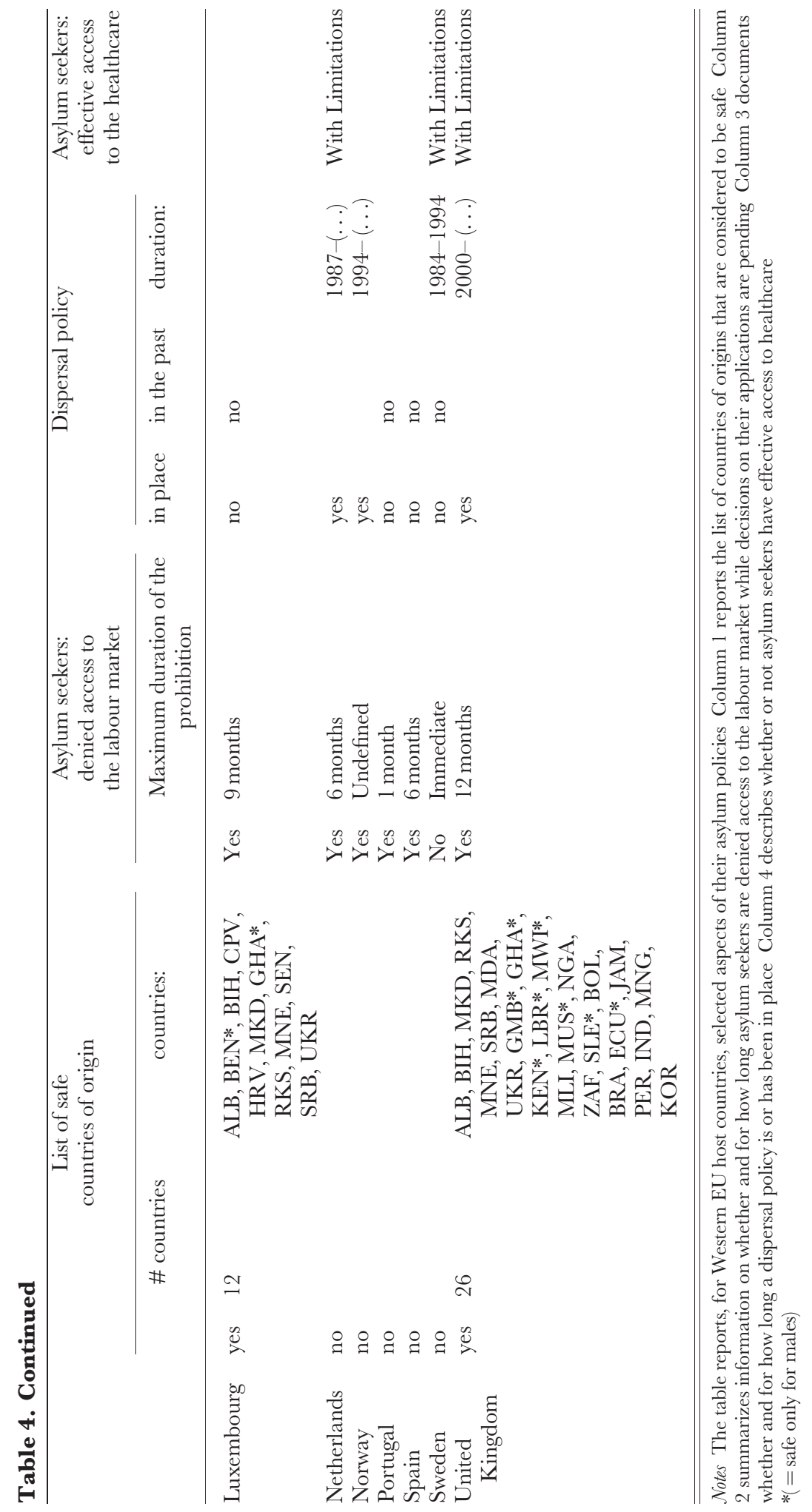


ensure that asylum seekers access the labour market no later than 9 months after they apply for protection. This ban, however, is for only 1 month in Portugal; 3 months in Austria, Finland, and Germany, 6 months in Belgium, Italy, Netherlands and Spain, but one year in France and the UK.

Over the last few decades, European countries have also experimented with asylum seeker dispersal policies aimed generally at distributing the inflows of potential refugees across different regions of the receiving countries, usually away from major cities. Sweden, for example, introduced an 'all-of-Sweden' policy in 1984 that remained compulsory until 1994 (Edin et al., 2003). Denmark similarly implemented a dispersal policy between 1986 and 1998 (Damm, 2009), and in 1987 and 1994, respectively, the Netherlands and Norway introduced dispersal policies that still remain in place today. The UK and Ireland also continue to disperse asylum seekers under policies introduced in 2000 (Bell et al., 2013). At the same time, according to AIDA ${ }^{12}$ survey data, only Belgium, Italy and Ireland fully guarantee asylum seekers adequate access to healthcare: in all other countries, they enjoy only limited access.

\section{THE CURRENT EUROPEAN REFUGEE CRISIS}

\subsection{Entry routes}

According to Frontex, which records detected attempts since 2009, over 2.6 million illegal migration attempts were detected at European borders between 2009 and 2015, with 1.8 million in 2015 alone. ${ }^{13}$ Frontex distinguishes nine routes of entry into Europe: (1) the central Mediterranean route (i.e. flows from North Africa towards Italy and Malta through the Mediterranean Sea); (2) the circular route from Albania to Greece; (3) the eastern border route (i.e. the $6,000 \mathrm{~km}$ long land border between Belarus, Moldova, Ukraine, the Russian Federation and the EU's eastern Member States); (4 and 5) the Eastern Mediterranean sea and land routes (i.e. crossing through Turkey to the EU via Greece, southern Bulgaria or Cyprus); (6) the Western African route (mainly from Senegal and Mauritania to the Canary Islands); (7 and 8) the western Mediterranean sea and land routes (from North Africa to the Iberian Peninsula); and (9) the Western Balkan route (i.e. flows from the Western Balkan countries themselves and crossings through the Bulgarian Turkish or Greek Turkish borders directed towards Hungary).

Figure 6 outlines the numbers of illegal border crossings recorded by Frontex over time while also highlighting the share of crossings through each of the three routes that

12 The European Council on Refugees' Asylum Information Database (AIDA).

13 Illegal crossings are defined as 'the number of third country nationals detected by Member State au thorities when entering or attempting to enter illegally the territory between border crossing points at external borders'. See Data Appendix A.2 for a discussion of the limitations of these data. 


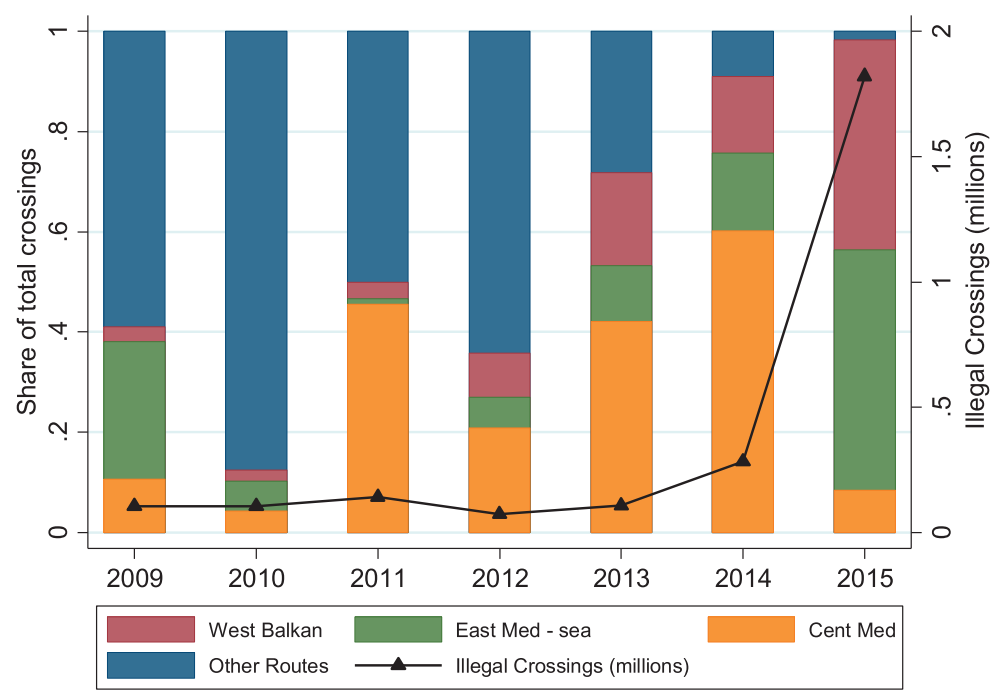

Figure 6. Illegal border crossings in Europe by route (2009-2015)

Notes: The solid line and right axis represent the annual number of detected illegal border crossings (in millions) into the EU between 1980 and 2015; the vertical bars report the share of total crossings in each year detected on the Western Balkan route (red), Eastern Mediterranean sea route (green), Central Mediterranean route (yellow) and other routes (blue).

Source: Authors' calculations based on Frontex data.

have become the most important in the current crisis: the Central Mediterranean route, the Eastern Mediterranean sea route and the Western Balkan route. The number of attempted illegal crossings rose dramatically between 2014 and 2015. The share of total crossings along the Central Mediterranean route was especially large in 2014 (about $60 \%$ of total crossings), while the Eastern Mediterranean sea and Western Balkan routes together accounted for 90\% of illegal crossing attempts in 2015.

\subsection{Source countries}

As regards origin country, over the entire 20092015 period, Syrian citizens, at about $38 \%$ of the total, constituted the largest group attempting illegal crossings, with the over 500 thousand Afghans making up an additional 20\% (see panel A, Table 5). ${ }^{14}$ Iraqis, Pakistanis, Albanians and Eritreans each accounted for 4 to $5 \%$ of total crossings, while those coming from Kosovo, Somalia, Nigeria and Bangladesh made up about $2 \%$. As illustrated by the ratio of illegal crossing attempts in 2015 to those in 2009 (column 4), over the 7 years covered by our data, the relative magnitude of inflows from each of these countries varied drastically, and total illegal

14 Because information on origin country is unavailable for 14\% of total crossings in Q3 2015 and $48 \%$ of total crossings in Q4 2015, for these two quarters, we impute unknown nationalities based on the route specific origin country composition in the previous quarter. 
Table 5. Illegal border crossings and asylum applications in Europe, 2009-2015

Panel A: Illegal crossings to Europe, 20092015

\begin{tabular}{lccr}
\hline Origin & Detected attempts & Share of total attempts $(\%)$ & Ratio 2015/2009 \\
\hline Syria & 992,864 & 37.7 & $1,430.92$ \\
Afghanistan & 529,595 & 20.1 & 28.98 \\
Iraq & 134,029 & 5.1 & 28.95 \\
Pakistan & 131,350 & 5.0 & 60.67 \\
Albania & 111,660 & 4.2 & 0.27 \\
Eritrea & 95,687 & 3.6 & 18.83 \\
Kosovo & 57,544 & 2.2 & 35.80 \\
Somalia & 54,451 & 2.1 & 2.12 \\
Nigeria & 48,491 & 1.8 & 14.41 \\
Bangladesh & 44,331 & 1.7 & 47.60 \\
Total & $2,633,896$ & & 17.41
\end{tabular}

Panel B: Asylum applications in Europe, 20092015

\begin{tabular}{lccc}
\hline Origin & Applications & Share of total applications (\%) & Ratio 2015/2009 \\
\hline Syria & 595,869 & 16.9 & 77.33 \\
Afghanistan & 360,542 & 10.2 & 8.10 \\
Serbia and Kosovo & 271,235 & 7.7 & 4.57 \\
Iraq & 214,471 & 6.1 & 6.51 \\
Eritrea & 151,754 & 4.3 & 4.95 \\
Russian Federation & 145,634 & 4.1 & 0.94 \\
Pakistan & 143,284 & 4.1 & 4.77 \\
Somalia & 126,815 & 3.6 & 1.00 \\
Nigeria & 108,889 & 3.1 & 2.51 \\
Albania & 107,817 & 3.1 & 32.91 \\
Total & $3,522,378$ & & 4.74 \\
\hline \hline
\end{tabular}

Notes: Panel A reports, for Europe as a whole, the number of detected illegal crossings of European borders be tween 2009 and 2015 separately for each of the ten main origin countries, the share of nationals from each origin country among total illegal crossings, the ratio of detected crossings in 2015 to detected crossings in 2009 and the number of years each country has been among the top ten origin countries in the period 20092015 .

Source: Our elaboration on Frontex data.

Panel B reports separately for each of the ten main origin countries the number of asylum applications filed in Europe between 2009 and 2015, the share of nationals from each origin country among total asylum applications, the ratio of applications in 2015 to applications in 2009 and the number of years each country has been among the top ten origin countries of applicants in the period 20092015.

Source: Own calculations on UNHCR data.

crossing attempts grew 17-fold. Nonetheless, expansions were not equally distributed across countries; for instance, unauthorized migration attempts from Syria accelerated dramatically from barely any in 2009 to 1.4 thousand times the number in 2015. Conversely, the number of illegal crossings attempted by Albanian citizens in 2015 was only one-third of its 2009 size.

Panel B of Table 5 shows that between 2009 and 2015, over 3.5 million asylum applications were submitted in Europe, with the number increasing nearly fivefold over the period. The top 10 countries of origin for asylum applicants largely overlap with those of illegal crossers, with 9 out of 10 countries being in both lists. Syria and Afghanistan particularly, the two countries that account for the greatest number of attempted illegal 
border crossings, are also the top two countries of origin for asylum applicants and were responsible for the largest increase in asylum applications (by a factor of 77 and 8, respectively). The exceptions are Russia, which is only present among countries of origin for asylum applicants, and Bangladesh, which is not among the top ten countries of origin of asylum applicants.

\subsection{Destinations}

As already emphasized, not all European countries (EU28 + NOR + CHE) have been equally affected by the refugee crisis. As Table 6 shows, between 2009 and 2015, Western European countries received the largest share (3.1 million) of the total 3.5 million asylum applications (almost 70 per 10,000 population) received by all European countries. ${ }^{15}$ These aggregate figures, however, conceal the true heterogeneity of refugee populations across Western European countries. As Table 6 shows, over the 20092015 period, the top five recipients of asylum applications were Germany (902 thousand; 110.1 per 10,000 pop.), Sweden (414 thousand; 446.9 per 10,000 pop.), France (390 thousand; 60.5 per 10,000 pop.), Italy (256 thousand, 43.5 per 10,000 pop) and Hungary (244 thousand; 243.8 per 10,000 pop.).

Figure 7 illustrates the relation between the total asylum applications received by each country between 2009 and 2015 (vertical axis) and its population of individuals with refugee status in 2009 (horizontal axis). The straight line is the equality line. The figure shows that the vast majority of European countries with the only exception being the UK lie above the equality line, implying that the number of applications received over the 2009 2015 period was larger than the accumulated stock of refugees hosted in 2009. The scatter plot further reveals that countries that started with a larger population of refugees in 2009 attracted more asylum applicants in the following years.

As a matter of fact, the burden imposed on Europe by this inflow of asylum seekers is small compared to that placed on countries closer to the refugees' countries of origin. This difference is clearly demonstrated in Table 7, which reports refugee stocks and their ratios to 10,000 population in both selected EU countries and Syria's neighbouring countries in 2014 (the last year for which complete data are available for all countries). At that time, Lebanon, a country with a population of 4.5 million, was hosting 1.16 million refugees, or about 2,554 individuals in search of humanitarian protection per 10,000 population. Likewise, Jordan was home to more than 1,000 refugees per 10,000 population, while Turkey was hosting nearly 1.7 million or 221 per 10,000 population. By comparison, Sweden, the EU country with the highest population of individuals with

15 Note that the figures refer to the number of applications, not the number of individuals filing an ap plication. Since individuals may be filing multiple applications, the number of applications is an upper bound for the actual size of the flow of asylum seekers over the period. 
Table 6. Total asylum applications in Europe between 2009 and 2015 by host country

\begin{tabular}{lcc}
\hline \hline Host country & \multicolumn{2}{c}{ Total asylum application 20092015} \\
\cline { 2 - 3 } & thousands & per 10,000 pop \\
\hline Germany & 902.7 & 110.1 \\
Sweden & 413.6 & 446.9 \\
France & 389.5 & 60.5 \\
Italy & 256.7 & 43.5 \\
Hungary & 244.5 & 243.8 \\
United Kingdom & 204.1 & 32.9 \\
Austria & 186.9 & 224.2 \\
Switzerland & 151.7 & 196.9 \\
Belgium & 147.2 & 136.9 \\
Netherlands & 127.4 & 77.3 \\
Norway & 98.7 & 205.7 \\
Greece & 73.1 & 65.8 \\
Denmark & 61.2 & 111.1 \\
Poland & 60.9 & 16.0 \\
Finland & 53.6 & 100.7 \\
Bulgaria & 41.3 & 55.3 \\
Spain & 34.2 & 7.4 \\
Cyprus & 14.0 & 175.5 \\
Ireland & 11.7 & 25.8 \\
Malta & 11.3 & 274.7 \\
Romania & 9.6 & 4.7 \\
Luxembourg & 9.1 & 184.7 \\
Czech Republic & 4.8 & 4.6 \\
Croatia & 3.8 & 8.7 \\
Slovak Republic & 2.8 & 5.3 \\
Lithuania & 2.3 & 7.1 \\
Portugal & 2.2 & 2.1 \\
Slovenia & 1.5 & 7.5 \\
Latvia & 1.4 & 6.4 \\
Estonia & 0.5 & 3.7 \\
& 3123.7 & 76.5 \\
EU15 + NOR + CHE & 3522.4 & 68.5 \\
EU28 + NOR + CHE & & \\
& & \\
& & \\
& &
\end{tabular}

Notes: The table reports for each EU host country (plus Norway and Switzerland) the total number, and the num ber per 10,000 population, of asylum applications received between 2009 and 2015 (in thousand). It also reports the stock of individuals with refugee status (full or subsidiary) living in the country in 2009 (in thousand), overall and per 10,000 population.

Source: Own calculations based on UNHCR data.

full GCR or subsidiary status relative to its size, was hosting 206 asylum seekers or individuals with refugee status per 10,000 population. The ratio for Norway and Switzerland was just above 100 per 10,000 population, and for Germany and France, it was only 55 and 47, respectively. 


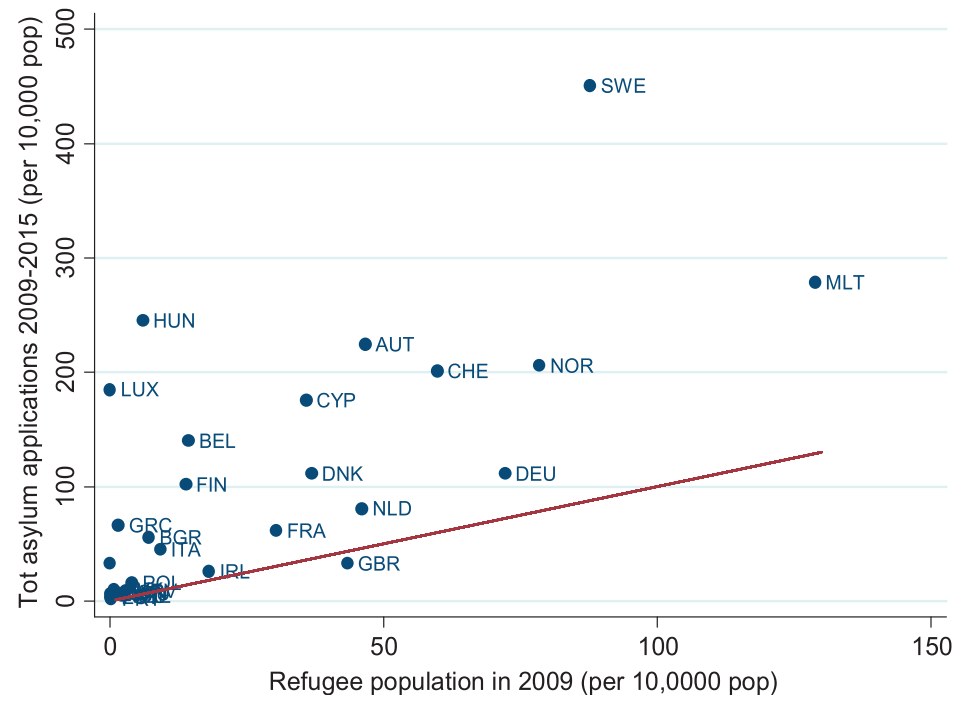

Figure 7. Total asylum applications received between 2009 and 2015 and refugee population in 2009 by host country

Notes: The horizontal axis displays the 2009 stock of individuals with refugee status (full or subsidiary) per 10,000 population for all EU countries (plus Norway and Switzerland); the vertical axis shows the cumulated number of asylum applications between 2009 and 2015 per 10,000 population. The straight line is the equality line above which countries were receiving a higher number of applications than their 2009 refugee stock.

Source: Authors' calculations based on UNHCR data.

\section{REFUGEE LABOUR MARKET INTEGRATION}

\subsection{Evidence from past refugee waves}

To assess how well past refugees to EU countries have integrated into the labour market compared to economic immigrants from the same area of origin we draw on the 2008 wave of the European Labour Force Survey (EULFS) that allows us to differentiate between economic and refugee migrants. ${ }^{16}$ We focus on individuals in working age (between 25 and 64 years old), not in full education or military service, and define 'refugees' the migrants who report 'international protection' as the reason for migration (see Data Appendix A.3 for details).

Table 8 gives an initial overview of the socio-economic characteristics of refugees compared to those of natives and economic immigrants from EU15 and non-EU15 countries. The refugees are $61 \%$ male, versus $47 \%$ for economic immigrants, and 43.9 years old on average, which is slightly older than economic immigrants but under a year younger than natives. They are on average somewhat less educated than natives

16 At the time this paper was written, this is the only available wave in the EULFS that provides that type of information. 
Table 7. Refugees and asylum seekers as a share of population, 2014

\begin{tabular}{|c|c|c|c|}
\hline \multicolumn{4}{|c|}{ Panel A: Middle Eastern countries } \\
\hline & Refugees & $\begin{array}{c}\text { Country } \\
\text { population }\end{array}$ & $\begin{array}{c}\text { Refugees per } \\
10.000 \\
\text { population }\end{array}$ \\
\hline Lebanon & $1,161,439$ & $4,546,774$ & 2,554 \\
\hline Jordan & 672,862 & $6,607,000$ & 1,018 \\
\hline Turkey & $1,693,686$ & $76,667,864$ & 221 \\
\hline Iraq & 279,585 & $34,812,326$ & 80 \\
\hline
\end{tabular}

Panel B: EU Countries (plus Norway and Switzerland)

\begin{tabular}{lcrrr}
\hline & $\begin{array}{c}\text { Stock of individuals } \\
\text { with refugee status } \\
\text { (full or subsidiary) }\end{array}$ & $\begin{array}{c}\text { Asylum } \\
\text { seekers }\end{array}$ & $\begin{array}{c}\text { Country } \\
\text { population }\end{array}$ & $\begin{array}{c}\text { individuals with } \\
\text { refugee status + } \\
\text { asylum seekers per } \\
10,000 \text { population }\end{array}$ \\
\hline Sweden & 142,152 & 56,717 & $9,644,864$ & 206 \\
Norway & 46,980 & 7,094 & $5,107,970$ & 106 \\
Switzerland & 62,566 & 20,762 & $8,139,631$ & 102 \\
France & 252,228 & 55,814 & $65,889,148$ & 47 \\
Denmark & 17,737 & 4,245 & $5,627,235$ & 39 \\
Germany & 216,921 & 226,116 & $80,767,463$ & 55 \\
United Kingdom & 117,093 & 36,294 & $64,351,155$ & 24 \\
Italy & 93,662 & 45,675 & $60,782,668$ & 23 \\
\hline \hline
\end{tabular}

Notes: Panel A reports the total number of refugees, the country's population and the number of refugees per 10,000 population in selected Middle Eastern countries in 2014. Panel B displays the total number of individuals with full Geneva or subsidiary refugee status, the total number of asylum applications, the country's population and the number of individuals with refugee status plus asylum seekers per 10,000 population in selected

European countries in 2014.

Source: Own calculations based on UNHCR data.

and economic immigrants from EU15 countries, but they are better educated than economic immigrants from non-EU15 countries.

To evaluate how refugee employment rates compare with those of economic immigrants and natives, in Figure 8, we graph unconditional and conditional (on age, gender and educational attainment) employment rate differentials between natives and, respectively, EU15 economic immigrants, non-EU15 economic immigrants and refugees overall. ${ }^{17}$ Although all immigrant types have lower employment probabilities than natives, both conditionally and unconditionally, the employment gaps are larger for non-EU15 immigrants than for EU15 immigrants (3.2 versus 7.2 percentage points unconditional on socio-economic characteristics) and increase to 16.1 percentage points for refugees.

17 The estimates are from LPM regressions of an indicator equal to one if the individual is employed (or self employed) on refugee, EU15 immigrant and non EU15 immigrant dummies, a set of individual controls and country of residence fixed effects. These estimates are reported in Appendix Table Al. We focus our analysis of refugees' economic integration on employment status because wage data are not available in EULFS data. 
Table 8. Basic characteristics of refugee population

\begin{tabular}{|c|c|c|c|c|}
\hline & Refugees & $\begin{array}{l}\text { Immigrants } \\
\text { non EU15 }\end{array}$ & $\begin{array}{l}\text { Immigrants } \\
\text { EU15 }\end{array}$ & Natives \\
\hline Share of males & 0.61 & 0.47 & 0.47 & 0.50 \\
\hline Mean age & 43.9 & 41.2 & 42.6 & 44.7 \\
\hline Share with lower secondary education & 0.38 & 0.44 & 0.27 & 0.32 \\
\hline Share with tertiary education & 0.23 & 0.22 & 0.28 & 0.26 \\
\hline Number of observations & 2,554 & \multicolumn{2}{|c|}{33,370} & 440,594 \\
\hline
\end{tabular}

Notes: The table compares socio economic characteristics of refugee migrants (who entered the country because of international protection), economic migrants from EU15 and non EU15 countries and natives. The sample in cludes all individuals aged between 26 and 64, not in education or military service.

Source: Own calculations based on the EULFS, 2008; EULFS 2008.

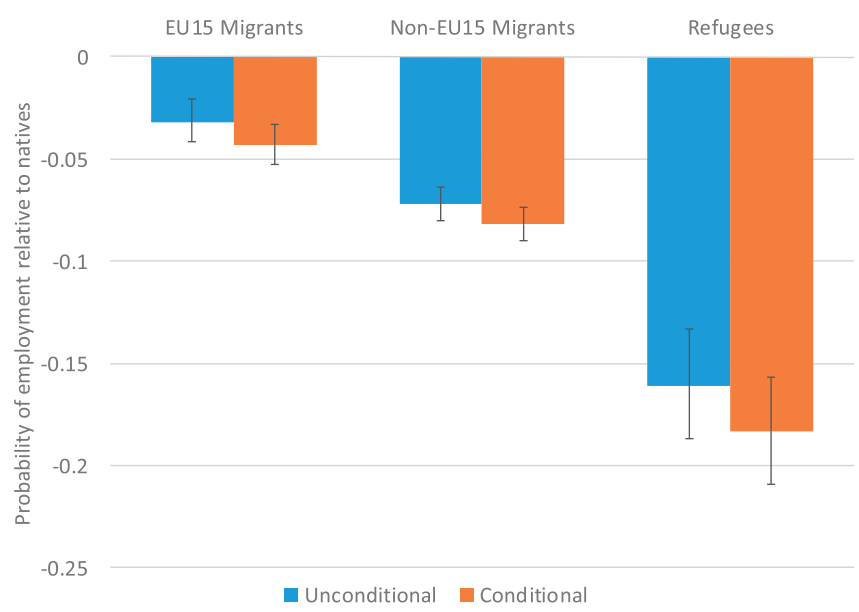

Figure 8. Refugee-native and immigrant-native employment gaps

Notes: The figure shows the unconditional and conditional differences in employment probabilities between EU15 and non EU15 economic immigrants and natives, as well as between refugees and natives obtained using linear probability models. All regressions include host country fixed effects. Conditional employment gaps control for gender, age (dummy variables for 5 year age groups) and education (dummy variables for lower secondary and tertiary education). The sample includes all individuals aged between 25 and 64 not in full time education or mili tary service. We also report $90 \%$ confidence intervals based on robust standard errors.

Source: Authors' calculations based on EULFS 2008 data.

Conditional employment gaps are even larger, reflecting the fact that refugees are disproportionately male and young, both of which characteristics are positively associated with a likelihood of employment. Figure 9 provides more detail on how the (conditional) immigrant-native and refugee-native employment gaps differ by area of origin. ${ }^{18}$

18 The estimates are from LPM regressions of an indicator equal to one if the individual is employed (or self employed) on refugee and immigrant dummies, a set of individual controls and country fixed ef fect, with separate regressions estimated for each area of origin. Information about the country of ori gin is not available. These estimates are reported in Appendix Table A2. 


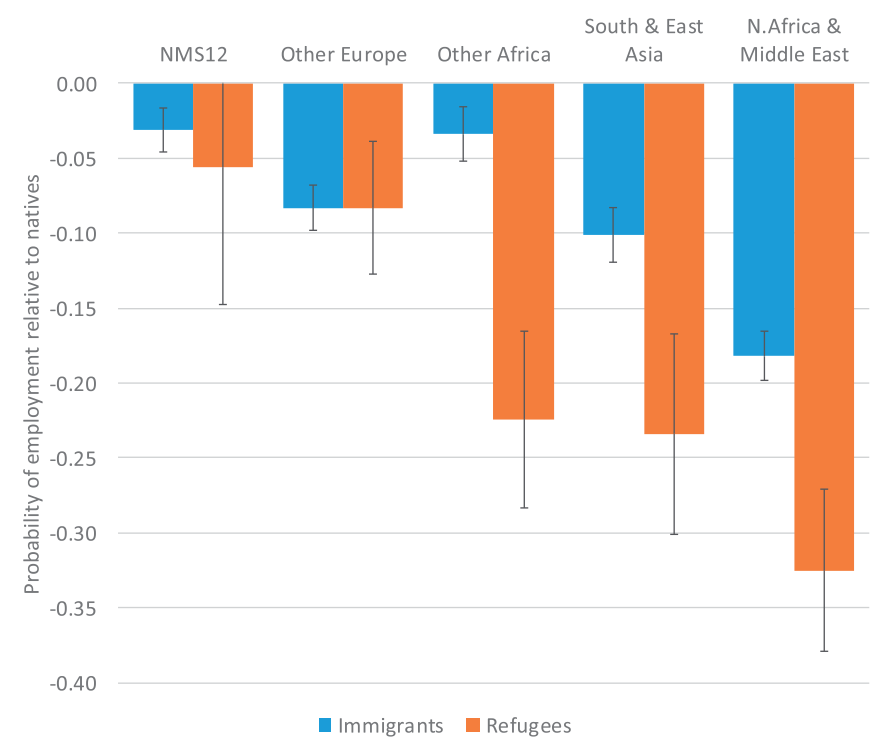

\section{Figure 9. Employment gaps by area of origin}

Notes: The figure displays the differences in employment probabilities between economic immigrants and natives and between refugees and natives by area of origin obtained using linear probability models estimated separately for each origin area. The regressions control for gender, age (dummy variables for 5 year age groups), education (dummy variables for lower secondary and tertiary education) and host country fixed effects. We also report $90 \%$ confidence intervals based on robust standard errors. The sample includes all individuals aged between 25 and 64 not in full time education or military service but excludes economic immigrants from EU15 countries. NMS12 in cludes all countries that entered the EU in 2004 and 2007: Malta, Cyprus, Estonia, Latvia, Lithuania, Poland, the Czech Republic, Slovakia, Slovenia, Hungary, Bulgaria and Romania.

Source: Authors' calculations based on EULFS 2008.

Whereas refugees and economic immigrants from European countries outside EU15 (NMS12 and Other European in the Figure) show similar conditional employment gaps to natives, refugees from North Africa, the Middle East or other African and Asian countries are considerably less likely to be employed than economic immigrants from the same areas of origin. Employment gaps are largest for the group of refugees from North Africa and the Middle East, at 32.5 percentage points.

To assess how quickly refugees integrate into their host countries vis-à-vis economic immigrants, in Figure 10 we plot the conditional refugee-native and immigrant-native employment rate differentials against years since arrival. As expected, the employment probabilities of both refugees and economic immigrants increase with years in the country; however, the increase is far steeper for refugees. During the first three years of arrival, refugees are 50 percentage points less likely to be employed than natives, a large gap that may be explainable by the legal restrictions on labour market participation frequently in place during the application processing period. This refugee-native employment gap declines by about half 7 to 10 years after arrival, turns statistically insignificant 15 to 19 years after arrival and eventually approaches zero 25 years after arrival. While the figure suggests that employment prospects of refugees improve more rapidly than those of immigrants with time in the country, it is important to bear in mind that the 


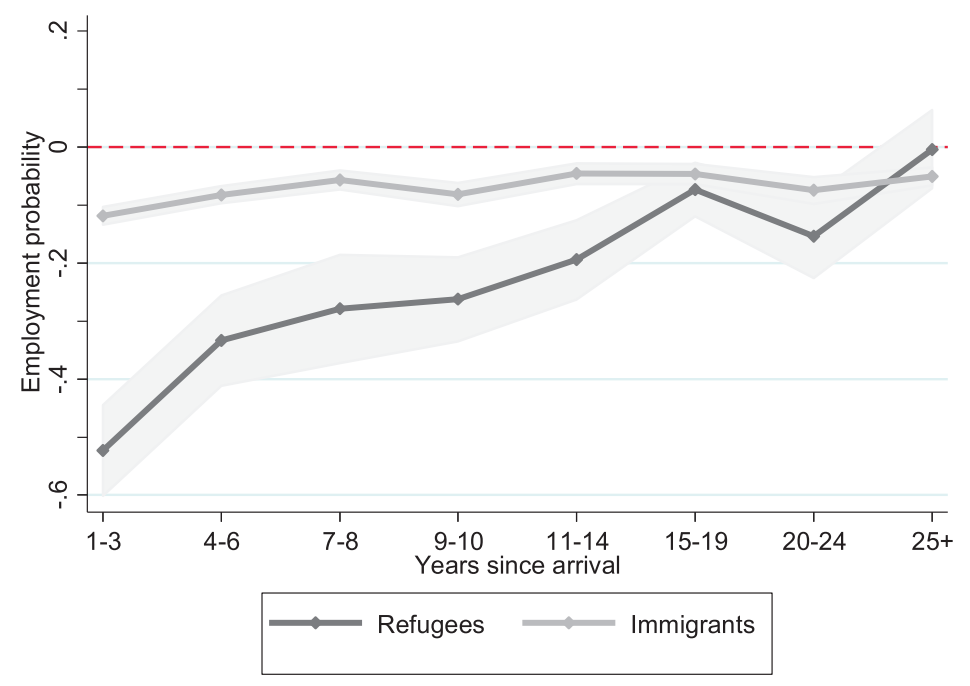

Figure 10. Employment gaps by years since arrival

Notes: The figure displays gaps (together with 90\% confidence intervals) in the employment probabilities of eco nomic immigrants versus natives and refugees versus natives by years since arrival obtained from linear probabil ity models that condition on gender, age (dummy variables for 5 year age groups), education (dummy variables for lower secondary and tertiary education) and host country fixed effects. The sample includes individuals aged between 25 and 64 not in full time education or military service.

figure is based on one cross-section only, precluding us from separating the effects of years since arrival from possible compositional changes across cohorts. This catch-up of refugees is in line with evidence presented by Aiyar et al (2016) who, similar to us, focus on Europe as a whole. Luik et al. (2016) and Cortes (2004) document a similar catch-up of refugees in Sweden and the United States. Bratsberg et al. (2014, 2016), in contrast, paint a more negative picture in the case of Norway, highlighting that refugees become increasingly dependent on social insurance transfers. ${ }^{19}$

Table 9 highlights that the lower employment probabilities of refugees versus immigrants cannot be accounted for by differences in area of origin or years since arrival. ${ }^{20}$ Conditional on individual characteristics and destination country fixed effects, refugees are 10.9 percentage points less likely to be employed than economic (non-EU15) immigrants. This gap decreases only slightly to 0.095 percentage points when area of

19 Bevelander and Pendakur (2014) find that in Canada refugees, especially women, tend to be more successful than family reunion immigrants.

20 In column (1), we regress the employment indicator on an indicator for being a refugee, an indicator for being foreign born (which equals 1 for both immigrants and refugees, and 0 for natives) as well as on individual characteristics and country of residence fixed effects. We then include a full set of inter actions between the foreign born indicator and indicators denoting years since arrival (column 2), be tween the foreign born indicator and indicators of area of origin (column 3) and between the foreign born indicator and indicators of both years since arrival and area of origin ones (column 4). In this specification, the coefficient on the refugee indicator refers the mean difference in the employment probabilities of refugees and non EU15 immigrants within each year since arrival (in column 2), within each area of origin (in column 3) or both (in column 4). 
Table 9. Refugee-Immigrant (non-EU15) employment gap

\begin{tabular}{|c|c|c|c|c|}
\hline & $\begin{array}{c}\text { Baseline } \\
\text { (1) }\end{array}$ & $\begin{array}{c}\text { Conditional on } \\
\text { years since arrival } \\
\text { (2) }\end{array}$ & $\begin{array}{l}\text { Conditional on } \\
\text { area of origin } \\
\text { (3) }\end{array}$ & $\begin{array}{l}\text { Conditional } \\
\text { on both } \\
(4)\end{array}$ \\
\hline Refugee immigrant gap & $\begin{array}{l}0.109 * * * \\
(0.017)\end{array}$ & $\begin{array}{l}0.121^{* * * *} \\
(0.017)\end{array}$ & $\begin{array}{l}0.083^{* * * *} \\
(0.017)\end{array}$ & $\begin{array}{l}0.095^{* * * *} \\
(0.016)\end{array}$ \\
\hline Years since arrival FE & & $\mathrm{X}$ & & $\mathrm{X}$ \\
\hline Area of origin FE & & & $\mathrm{X}$ & $\mathrm{X}$ \\
\hline Observations & 468,404 & 468,404 & 468,404 & 468,404 \\
\hline$R^{2}$ & 0.216 & 0.216 & 0.217 & 0.218 \\
\hline
\end{tabular}

Notes: We regress the usual employment indicator on an indicator for refugee, a foreign born one (which equals 1 for both immigrants and refugees, and 0 for natives) as well as the usual individual characteristics (age dummies, gender, education dummies) and country of residence fixed effects. We then, from column 2 onward include the refugee indicator and a full set of interactions between the foreign born indicator and years since arrival ones (col umn 2), between the foreign born indicator and area of origin ones (column 3) and between the foreign born indi cator and both years and area of origin ones (column 4). With such a specification, the coefficient on refugee (reported in the table) delivers the mean difference between employment probability of refugees and non EU15 immigrants within each value of year since arrival (in column 2) and within each area of origin (in column 3) or within both (in column 4). Sample: individuals aged between 25 and 64, not in education or military service. Immigrants from EU15 or North America are excluded. Robust standard errors in brackets.

$* * * p<0.01, * * p<0.05, * p<0.1$.

origin fixed effects and years since arrival are included as additional regressors. Compositional differences in terms of years since arrival and areas of origin are, therefore, responsible for only a relatively small portion (13\%) of the observed employment gap between refugees and non-EU15 immigrants.

Figure 11 further reveals that the refugee-native employment gaps (conditional on individual characteristics) vary widely across destination countries, much more so than the economic immigrant-native employment gaps. The two countries with the largest refugee-native employment gaps are Ireland and the UK (with 46 and 29 percentage points, respectively), both nations in which economic immigrants do particularly well. ${ }^{21}$ Countries with a relatively large refugee share, such as Sweden, Germany and Austria, take a middle position with employment gaps of 23, 17 and 9 percentage points, respectively. Finally, employment gaps between natives and both refugees and economic immigrants are small in Cyprus and Greece, as well as in Italy, Spain and Portugal, all countries with relatively low shares of refugees.

\subsection{Outlook: the current refugee crisis}

How well current refugees will integrate into the labour market is extremely difficult to forecast for at least two reasons. First, comprehensive and representative data on the skill

21 Despite such heterogeneity, estimates from the pooled sample of all countries are not driven by any single country. Table A3. reports estimates from pooled regressions where we drop at a time each of the countries in our sample. The immigrant and refugee coefficients remain highly significant and are of similar magnitude across all specifications. 


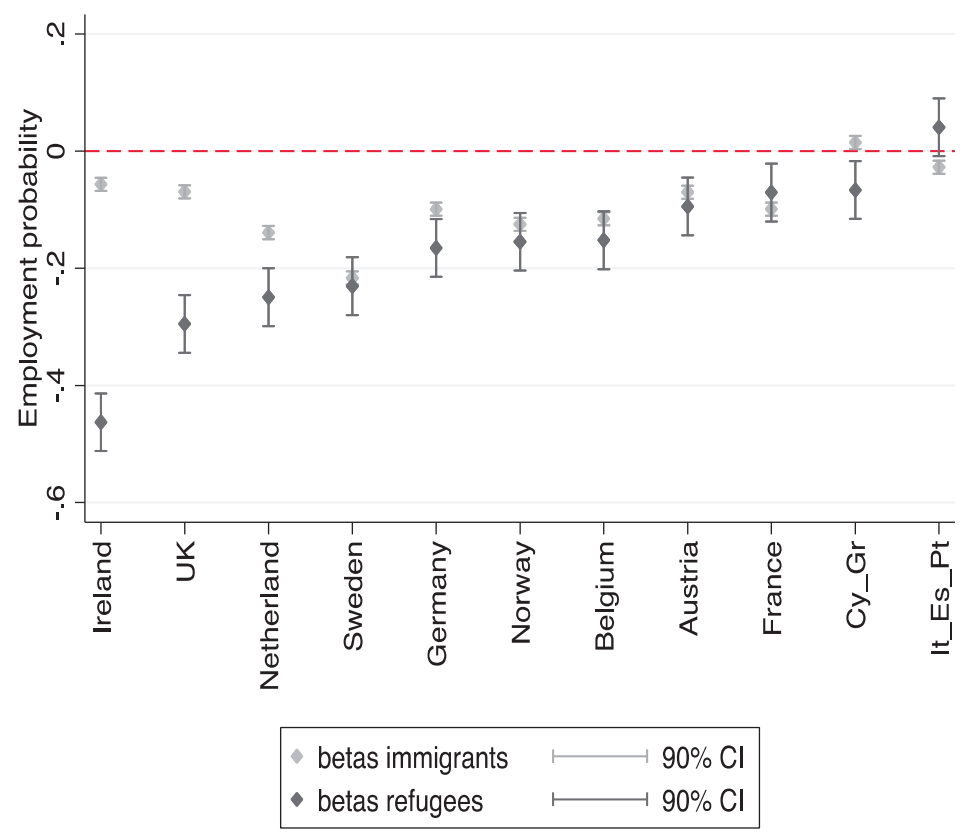

\section{Figure 11. Employment rate differentials by host country}

Notes: The figure plots employment rate differentials (and 90\% confidence intervals) between economic immi grants and natives as well as between refugee migrants and natives separately by host country, obtained from lin ear probability models estimated separately for each country that condition on gender, age (dummy variables for 5 year age groups) and education (dummy variables for lower secondary and tertiary education). Due to the low number of refugees in some countries, Italy, Spain and Portugal (It Es Pt) are grouped together, as are Cyprus and Greece $(\mathrm{Cy}$ Gr). The sample includes all individuals aged between 25 and 64 not in full time education or military service.

structure and employability of those currently applying for asylum, or of those whose application was approved no more than two years ago, does not yet exist. Second, their labour market outcomes depend on which policies, integration support and incentive structures are implemented.

As Figure 9 shows, existing refugee populations in EU Member States who arrived many years before the current crisis, but who are from the same areas as the major share of current asylum seekers (i.e. North Africa and the Middle East), are considerably less likely to be employed than refugees from other areas, even conditional on their educational background.

A recent survey by the German Ministry for Immigration and Refugees conducted in 2014, which focuses on individuals given official refugee status who initially applied for asylum in Germany between 2007 and 2012 and thus arrived at the onset of the crisis, further indicates that refugees from Syria, Iraq and Afghanistan are less educated than refugees who arrived in previous waves. Specifically, as Table 10 shows, $16.1 \%$ of Syrian and 25.9\% of Iraqi refugees have never attended school, and only 4.3 and $3.5 \%$ have attended school for at least 15 years (which is comparable to tertiary education in Table 8). The table further shows that only $38.9 \%$ of Iraqi and $24.7 \%$ of Syrian refugees are employed (of 
Table 10. Educational attainment and employment probabilities of recent refugees in Germany

\begin{tabular}{|c|c|c|c|c|c|c|c|c|}
\hline & \multicolumn{4}{|c|}{ School attendance } & \multicolumn{4}{|c|}{ Labour market participation } \\
\hline & None & $\begin{array}{l}\text { up to } \\
9 \text { years }\end{array}$ & $\begin{array}{l}1014 \\
\text { years }\end{array}$ & $\begin{array}{l}\text { at least } \\
15 \text { years }\end{array}$ & employed & $\begin{array}{l}\text { looking } \\
\text { for work }\end{array}$ & $\begin{array}{l}\text { out of the } \\
\text { labour force }\end{array}$ & in training \\
\hline Afghanistan & 18.3 & 27.8 & 48.9 & 2.8 & 29.1 & 20.7 & 19.9 & 16.3 \\
\hline Iraq & 25.9 & 41.4 & 25.7 & 3.5 & 38.9 & 21.5 & 26 & 6 \\
\hline Syria & 16.1 & 35.5 & 41.5 & 4.3 & 24.7 & 26.4 & 27.8 & 6.9 \\
\hline $\mathcal{N}$ & \multicolumn{4}{|c|}{2,403} & \multicolumn{4}{|c|}{2,805} \\
\hline
\end{tabular}

Notes: The table summarizes results from a recent survey conducted by the German Ministry for Immigration and Refugees in 2014, which focuses on individuals who obtained official refugee status and who initially applied for asylum in Germany between 2007 and 2012.

Source: Worbs and Bund (2016), table 2 and figure 4.

which roughly one third are employed only marginally for under $10 \mathrm{~h}$ a week), while onefifth to one quarter are looking for work (see Worbs and Bund, 2016, for more details).

Focusing on refugees who applied for asylum in Germany in 2015, a survey conducted by the German Ministry for Immigration and Refugees at the time of registration paints a somewhat more optimistic picture and puts the share of asylum applicants with tertiary education at $17 \%$ and the share of applicants who never attended school at $8 \%$. These numbers may, however, not be fully representative as only $70 \%$ of asylum applicants agreed to participate in the survey.

\section{THE ECONOMICS OF REFUGEE MIGRATION}

We begin our discussion on the economics of refugee migration by highlighting the important differences between refugee and economic migrants (Section 5.1.). We then discuss the trade-offs and policy options faced by single countries (Section 5.2.) before outlining the economic advantages of coordinated decisions between countries; for example, at the EU level (Section 5.3.).

\subsection{Refugee versus economic migrants}

Economic migrants are, at least conceptually, fundamentally different from refugee migrants in that the former not only choose whether or not to migrate, but also decide based on the constraints set by receiving countries, which country to migrate to given the economic benefits of this decision. Refugee migrants, in contrast, are forced to leave their origin countries, often due to unforeseen and sudden events that put their lives at risk. Their migration decisions, therefore, are generally neither deliberate nor planned, and less based on economic considerations. Their arrival in a host country is often dictated by contingency, after perilous and unpredictable journeys. Similarly, receiving countries typically choose economic migrants based on economic considerations (e.g. labour market shortages) and they can set clear migration terms, such as stay duration and migrant 
qualifications. In the case of refugee migration, however, countries are fulfilling their obligations as GCR signatories, and the decision to grant asylum seekers official refugee status is primarily based on humanitarian considerations. As such, receiving countries may have relatively little influence on the type of refugees they host. Refugee migrations are, therefore, closer to 'forced marriage' than the 'chosen match' typical in economic migrations and the relation between the two parties, migrant and destination country, is different from what would have evolved if all decisions had been taken on purely economic grounds. This is not to say that the forced marriage is necessarily inferior to the optimally chosen match for both parties. On the contrary, forced emigration may well mean that destination countries are able to attract migrants with qualifications and economic potential that they might otherwise not have enticed to settle in their countries. ${ }^{22}$ Cases also exist, however, of less well-endowed refugee populations where the economic benefit to the receiving country is less clear see our discussion in the previous section.

\subsection{Country-specific policies and trade-offs}

5.2.1. Permanent settlement or temporary protection? Even though destination countries have limited control over the number and type of displaced migrants arriving in their territory, they can decide whether to grant full GCR refugee status or offer subsidiary forms of humanitarian protection that require refugees to repatriate once the conflict or migration trigger has been eliminated. For instance, whereas in the 1990s, most destination countries opted for some form of temporary protection for the refugee waves from Bosnia and Kosovo, the choices made during the current refugee crisis differ widely (see Table 3). Many of the former Yugoslavia refugees returned to their home country once the conflict ended. For example, of the 345,000 refugees from Bosnia Herzegovina residing in Germany in 1996, 260,000 had voluntarily returned by December 2000, while 5,500 were deported against their will (Rühl and Lederer, 2001). In the current crisis, not only is there considerably more uncertainty about whether and when the primary impetuses for asylum seeking will abate, but current refugees are culturally more distinct than the Balkan refugees and, based on initial evidence, may also be less educated (see Section 4.2.).

Two primary reasons for the poor success in integrating refugees into the host countries' labour markets are the long decision time for asylum claims and the indecisiveness of host nations about duration and permanence of stay. Both factors contribute to considerable delays in giving individuals a clear perspective on their future residence in the

22 Historical incidences of the gains to countries giving refuge to persecuted populations include the 17 th century re population and boost to the textile industry in war torn Prussia induced by Huguenots fleeing religious persecution in France (see Hornung, 2014) and the major contributions to science and technology in the United States made by highly educated Jews fleeing Nazi Germany (see e.g. Moser et al., 2014). 
host country. This lack of clear timeframe speaks to the key insight from early dynamic models of human capital (e.g. Ben-Porath, 1967) that the longer the pay-off period for skill investment, the more individuals invest, which is why full time schooling takes place at the start rather than in the middle or towards the end of an individuals' life cycle. Applied to migrants, because the type of human capital that is productive differs across nations, migrants must learn new skills that make them productive in their new country of residence. One such skill is knowledge of the local language, whose acquisition is very costly but of dubious value in the origin country. Consequently, as emphasized by Dustmann (1993, 1999, 2000), whether and how much a migrant chooses to invest into country-specific human capital depends greatly on the migrant's perception of the likelihood of future settlement in the host country. Being unclear about the chances of permanent stay creates disincentives for investment into the types of skills that are productive in the new country, affecting the refugees' earnings and career paths and leading them to perform below their economic potential. ${ }^{23}$ Lack of clarity about the possibility of permanent settlement thus obstructs attempts to use such schemes to train refugees. Even if permanent residence is guaranteed but only after a prolonged period in the host country, such investment may no longer seem optimal because of the reduced pay-off period. Adda et al. (2016) find strong support for this hypothesis, by estimating a dynamic model of return migration and human capital accumulation, and simulating the effects of lack of clarity about permanence at the start of an individual's migration cycle on lifetime earnings and human capital investments.

These observations have important consequences for the politics of refugee migration. Above all, policies aimed at fostering labour market integration and optimizing migrants' economic contribution need to recognize that these individuals will only undertake costly investments in host country-specific human capital if they are likely to pay-off over the life cycle. Moreover, because certification requirements and the transferability of certain aspects of such capital differ across countries, any such policies need to be carefully adapted to the particularities of the host country. ${ }^{24}$ As a result of the above circumstances, refugees who are initially offered only temporary protection but end up staying for long periods may have lower employment probabilities and lower earnings than refugees offered permanent settlement from the start. This observation calls for

23 For example, Germany's comprehensive system of skill certifications obtained through 23 year trade apprenticeships is costly because remuneration during the long training period is far lower than the wage in an equivalent unskilled job (see Dustmann and Schoenberg, 2012, for details). Moreover, the certification, although valuable in Germany, may be worth little in the refugee's country of origin. Consequently, even young refugees are likely to be reluctant to undertake prolonged and costly train ing within the apprenticeship system unless they see their future in the Germany.

24 For instance, whereas certificates are an essential part of German workers' careers, such is less the case for UK workers. On the other hand, English may be more valuable in the home country than German. All else being equal, both these aspects support the economic integration of refugees into the UK rather than Germany. 
shorter periods for deciding asylum claims ${ }^{25}$ and for policies that provide clear host country commitment on residence duration. Such policies should be combined with carefully designed active integration programs for those who obtain full refugee status or permanent residency. ${ }^{26}$ The refugees' own investments could be further incentivized by making economic success in the labour market a pre-condition or contingency in the selection for permanent residence. In fact, Germany adopted such a policy in the 1990s for refugees from Bosnia and Kosovo (see, e.g. Rühl and Lederer, 2001; Rühl et al., 2004).

5.2.2. Where should refugees be allocated? In addition to choosing between permanent and temporary protection, destination countries must decide on refugee location, which economic efficiency dictates should be in areas with the lowest hosting costs but highest chances of integration into the labour market. Such areas tend to be urban areas already containing immigrants from the refugees' own country, who can then serve as a support network and actively help their newly arrived compatriots to find decent-paying jobs (Edin et al., 2003; Damm, 2009). For the same reasons, refugees also typically prefer areas with a larger concentration of their own nationals, meaning that allowing refugees free choice over where to locate within the destination country may lead to superior labour market outcomes.

Another important consideration is the political costs of refugee allocation. Recent research by Dustmann et al. (2016) suggests that the political costs may likewise be smaller in urban than in rural areas: they find that the inflow of refugee migrants increases the support for right-wing anti-immigration parties in rural areas, but not urban areas. On the other hand, housing costs are typically considerably higher in urban than in rural areas.

\subsection{Economic advantages of coordinated decisions between countries}

Increased coordination between countries for example, at the EU level could have several economic benefits for receiving countries that are separately discussed below.

5.3.1. Refugee status as a public good. Offering refugee status is a public good in that if one country offers asylum to those escaping individual persecution or civil war, residents in other countries benefit from knowing that these individuals are safe. However, the fact that the costs of hosting the refugees are borne entirely by the country providing asylum leads to an under-provision of the public good when countries make such decisions individually. Coordination between countries would make it possible to internalize the

25 Hainmueller et al. (2016) provide evidence that the length of time that refugees wait for a decision on their asylum claim affects their subsequent economic integration.

26 Couttenier et al. (2016) provide evidence that integration policies, including swift access to the labour market, can mitigate immigrants' likelihood to commit a crime. 
externalities that countries impose on each other, allowing the social optimum to be reached (see Hatton, 2004, 2015; Hatton and Williamson, 2006, for a formal analysis). ${ }^{27}$

Dynamically consistent decisions: A lack of coordination may induce countries to make decisions that are not dynamically consistent. For example, governments may deter applications for asylum by adopting specific policies, such as limiting asylum seekers' access to the labour or housing markets, implementing an especially lengthy application process or failing to provide an active integration program for successful applicants. These polices, as previously pointed out, can increase a destination country's cost of refugee hosting by hindering the integration of successful applicants. If, however, countries cooperate, they no longer have any incentive to adopt such harmful policies.

\subsubsection{Allocating a given number of refugees at the lowest possible cost.}

As shown by Fernández-Huertas Moraga and Rapoport (2015a,b), cooperation across nations makes it possible to allocate a given number of refugees at minimum costs while simultaneously ensuring that the burden (or responsibility) of providing refuge is shared by all countries. Supposing that countries have not only agreed on the total number of refugees to be admitted, but also on a refugee quota system (based, e.g. on country population size and GDP), ${ }^{28}$ then, ignoring for the moment any match effects whereby certain types of refugees can best integrate in a particular country, these countries will differ with respect to their (marginal) costs of providing refugee. Here, we interpret 'costs' in the broad sense, reflecting not only monetary costs but also the country's general willingness to welcome refugees. A market in which countries are allowed to trade refugee quotas will secure the allocation of refugees across countries at minimum costs. To illustrate this consider two countries, A and B, that initially agree to accept 1,000 refugees each. If the cost of hosting an additional refugee is $€ 20,000$ for country A but only $€ 10,000$ for country B, then there is room for trade. For example, country B might admit an additional refugee if paid at least $€ 10,000$, while country A might be willing to pay up to $€ 20,000$ for not having to provide refuge to the 1,000th refugee. The gains from the trade will be exhausted once the marginal costs of hosting an additional refugee are equalized between the two countries, resulting in a refugee allocation that minimizes the costs of granting asylum and allows both countries to contribute to the costs according to a prearranged quota. ${ }^{29}$ As argued by Fernández-Huertas Moraga and Rapoport (2015b), this mechanism may be augmented by a matching algorithm that allows

27 Facchini et al. (2006) develop a political economy model to study the process through which countries determine their asylum policies. They show that coordination is desirable, but allowing for cross country transfers towards countries that receive larger numbers of asylum seekers may lead to a wel fare inferior outcome because the possibility of compensation exacerbates strategic delegation effects.

28 Several such quota systems have been proposed in the past; see, for example, Fernandez Huertas Moraga and Rapoport (2015a) for an overview.

29 It should be noted that only a market mechanism can induce countries to truthfully reveal their costs of hosting refugees: when countries implement quotas dependent on costs, they have an incentive to overstate them. 
refugees to state their preferences for country of residence so as to realize match-specific gains between refugee and host country.

\section{DISCUSSION AND CONCLUSIONS}

In this paper, we provide a comprehensive overview of the existing regulatory frameworks for refugee migration, the magnitudes and types of refugee movements and the economics and politics of the current refugee crisis. In particular, we identify strong differences in the way EU countries interpret their obligations as signatories of the GCR and outline previous (mostly unsuccessful) attempts to enhance coordination at the EU level. We also demonstrate that although asylum claims in the EU are currently at an all-time high (1.5 million in 2015), applications are far from equally distributed across EU countries and only about 10\% submitted to EU15 countries (plus Norway and Switzerland) between 2000 and 2014 were successful. We further document that previous waves of refugee migrants have been less successful in integrating into European labour markets than economic migrants from the same origin areas. We also offer tentative evidence that the labour market outcomes of the current waves of refugees will be similarly problematic unless better integration mechanisms are implemented.

In our view, the above evidence calls for a strong, coordinated policy response to the current crisis, which has imposed on Europe the tremendous costs of large-scale movements of people who arrive unexpectedly and are given current regulations and their common interpretations hard to control using conventional border protection means. These movements pose an enormous challenge to European countries and to the fundaments of the EU as a whole. Not only their economic costs, but also their political costs threaten to create rifts between countries and furnish a welcome vehicle for populist movements to enhance their vote shares. ${ }^{30}$ The current crisis further demonstrates that the Dublin Convention is unworkable, as amply illustrated by Europe's unpreparedness for the number of refugees that have arrived at its southern borders. At the same time, the burden on EU countries of large inflows of refugees has been unequally distributed, and ex post re-allocation schemes to share this burden more equally have been impossible to implement. Moreover, many of those who arrived in European Member States over the past decade have migrated for economic reasons rather than because of valid claims under the GGR. Hence, only a fraction is likely to attain some type of refugee status (see Figure 5), which adds the problem of deporting unsuccessful asylum applicants.

Despite the challenges to coordinate policies, there is a drastic need for a new regulatory framework agreeable to all Member States that addresses the current and future challenges of refugee migration and replaces dated coordination attempts like the Dublin Convention with a more workable alternative. Such a framework should be based on two pillars: a coordinated policy that secures Europe's outer borders and deals 
with asylum claims before refugees have (illegally) crossed into mainland Europe, and an allocation mechanism that more equitably distributes the burden of refugee migrations across countries yet is flexible enough to account for national particularities and political circumstances.

On the first, a coordinated refugee policy should implement measures for deciding asylum claims at the outer borders of the EU before refugees enter the EU mainland. Such measures would need EU countries to agree in principle on exactly what constitutes a valid refugee claim. In practice, they would also require the establishment of facilities able to deal with large numbers of refugees at the outskirts of the EU, and of EU courts that decide within weeks on claims according to agreed rules and interpretations of the GCR. On the second, once some form of refugee status has been granted, the refugee needs then to be allocated to a European country, possibly with the help of tradable refugee quotas, combined with ex ante agreed allocation mechanisms that could take into account refugees' preferences, and seek to reduce the economic and political costs of refugee hosting. EU-level coordination that reduces the costs of refugee hosting could benefit all EU countries, not only those currently hosting the lion's share of asylum seekers. Such a system, if successfully implemented, would also deter potential migrants with no humanitarian reasons, and thereby reduce future flows, possibly quite radically.

Admittedly, establishing such a policy and its corresponding structures would be tremendously challenging. However, continued lack of ex ante coordination and absence of agreed EU-wide rules when dealing with future challenges may be far more costly. The demographic developments in Africa and the Middle East, and the potential for conflict in these regions suggest that there will be similar challenges in the future. Canning et al. (2015), in a World Bank report, estimate that the population of Africa, Europe's southern neighbour, will increase to 2.8 billion over the next 45 years, from 1.11 billion in 2013. Similar projections are provided by a recent (2015) UN report on the World Population, ${ }^{31}$ which identifies Africa as the continent with the fastest growing populations over the next decades, while Europe's populations are shrinking. This, in combination with sluggish economic development, climate change, unstable political leadership and possibly continued conflict, will lead to increased migration pressures on Europe. ${ }^{32}$ Among the 20 countries ranked highest according to the 2016 Fragile States Index by the Fund for Peace (used by the OECD in their Report on States of Fragility), ${ }^{33} 17$ are located either in Africa (14) or in the Middle East (3), and often overlap with countries

31 https://esa.un.org/unpd/wpp/Publications/Files/World Population 2015 Wallchart.pdf

32 Climate change induced phenomena such as desertification and scarcity of food is considered by some as possible future driver of large flows of 'climate refugees', especially from the Sahel region of Africa (see http://time.com/4024210/climate change migrants/).

33 See http://www.oecdilibrary.org/docserver/download/4315011e.pdf?expires 1469989086\&id id\& accname guest\&checksum BD6D76E71DCEE19C1258F41351FD4163 for the OECD report, and http://fsi.fundforpeace.org/rankings 2016 for the index. 
with the highest population growth. Europe's economic and political future will be severely affected on how it manages future movements instigated by conflict, persecution and deprivation. The current crisis is a wake-up call to develop the necessary institutions and implement needed coordination to be prepared for future challenges. ${ }^{34}$

The current crisis calls also for foreign policies that are more responsible. The recent and ongoing conflicts in the Middle East are the main reasons for the humanitarian disaster and the ensuing refugee flows we have witnessed over the past years. Responsibility for interventions and policies that may have contributed to the current situation lies also with European countries. ${ }^{35}$ To prevent refugee movements in the future, European foreign policy should learn from past experiences, and be aimed at avoiding conflict and instability.

\section{Discussion}

\section{Uwe Sunde}

\section{University of Munich}

This paper provides a very timely perspective on the economics of refugee migration. It describes the legal and institutional background of asylum and refugee status, gives an up-to-date description of the current European refugee crisis and provides an economic perspective on the issue, with a focus on the differences between economic and refugee migration. The paper ends with a discussion of aspects related to labour market integration and settlement policies. The bottom line of the paper is a call for coordination of refugee-related policies in Europe to overcome the challenges of the current crisis. Overall, the paper provides an important contribution to the debate on how to deal with the wave of refugees coming to Europe.

34 We should emphasize that we propose a coordinated system to deal with future refugee migrations. We believe that economic migrations should be handled sovereignly by the different Member States.

35 For example, see a recent report of the UK House of Commons Foreign Affairs Committee on the role of the UK government and its former Prime Minister David Cameron in the Libyan conflict (http://www.publications.parliament.uk/pa/cm201617/cmselect/cmfaff/119/11902.htm ). It states that the UK and French led intervention in 2011, supported by the United States, 'was not informed by accurate intelligence' and that by summer 2011 the 'limited intervention to protect civilians had drifted into an opportunist policy of regime change'. It let to 'political and economic collapse, inter militia and inter tribal warfare, humanitarian and migrant crises, widespread human rights violations, ........ and the growth of ISIS in North Africa'. One conclusion of the report is that 'former Prime Minister David Cameron was ultimately responsible for the failure to develop a coherent Libya strategy'. 
The paper poses several issues that deserve more research in the future. One of the central points of the paper is the documentation of the heterogeneity in refugee policies across Europe. This heterogeneity is partly rooted in the incompatibility of the reasons for the current crisis which is caused by civil conflicts and the population-wide mobility induced by these conflicts with the definition of a refugee in the GCR from 1951 which is based on a personalized concept of persecution faced by an individual. Since individual persecution needs to be documented in each asylum application, there are many degrees of freedom as to how the rules for the recognition of refugee status are interpreted, how strict the rules for recognition are, for how long unrecognized asylum seekers are kept in line with the non-refoulement rules, how strictly the rules are enforced and so on. This naturally implies an issue for the reliability and comparability of data, for instance, regarding the shares of those originally covered by the Geneva Convention in each country, and regarding the approval rates and return rates.

An interesting finding in this context is that the efficiency of asylum policies, measured by the clearing speed of asylum applications, does not appear to reveal a clear relation with the total number of applications in the data provided by the UNHCR. This is demonstrated in Figure 4 and points to an endogeneity of the approval policies. This graph is slightly misleading, however, since it plots time averages against time averages and thereby eliminates a lot of potentially interesting variation. This is illustrated by the cases of Germany and the UK, which exhibit entirely different dynamics, see Figure 12. While the UK used to receive a much higher number of applications than Germany during the early 2000s, this has reversed in the recent past. Obviously, there are issues of crowding dynamics and policy endogeneity that deserve to be studied in greater detail than is possible here. The key issue, however, is that time averages might conceal important dynamics in applications, decisions and possibly rejections.

An issue that is discussed in quite some detail refers to the fundamental difference between refugee migration and economic migration. The authors draw the distinction by implying that refugee migration constitutes a forced match whereas economic migration is the result of a deliberate and (potentially constrained) optimal choice. These differences are relevant for country-specific policies and have important economic
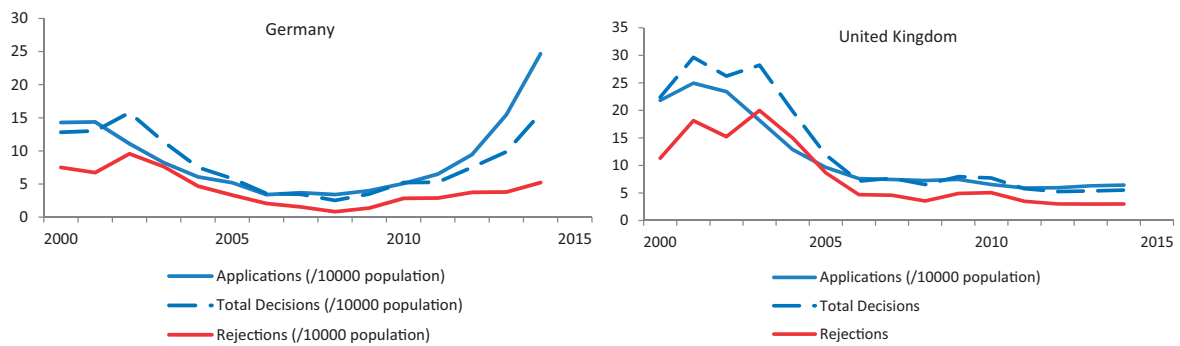

Figure 12. Shares of Asylum Applications and Applications Gleared Source: UNHCR. 
implications. For instance, the question of temporary versus permanent residence influences the incentives for investments, in particular into human capital. The authors indicate that refugee allocation within host country might be overly restrictive in this context and document the substantial heterogeneity in policies. They also point at the advantages of coordinated asylum policies, in light of the interpretation of refugee status as a public good.

The defining aspect of forced versus free migration appears somewhat extreme in this context. In particular, it seems hard to defend that refugees do not make decisions regarding migration, the timing of their flight, their destination country and their preferred location within the destination countries. Clearly, the choices are much more constrained than those of economic migrants, and the reasons for migrating differ. On the other hand, the fact that there seem to be substantial responses to policy changes suggests that this distinction might be overly restrictive.

An interesting example in this context is the ruling of the German Federal Constitutional Court regarding the entitlements of asylum seekers for welfare benefits. ${ }^{36}$ On 20 June 2012, the court criticized the discrepancy between welfare entitlements of German citizens and the benefits for asylum seekers and declared the large differences (of up to 50\%) incompatible with the constitution. In response to this ruling, the benefits for asylum seekers had to be increased substantially. Figure 13 plots the monthly total numbers of asylum applications in Europe over the period 2010 14. The data reveal that the ruling constituted a trend break in the asylum applications in Germany. While there is no clear pattern before the court ruling, the data show a very strong upward trend in applications in Germany after the ruling not witnessed by any other country. This seems to suggest that the match of refugees to a destination country is not fully random. Refugee migration, and in particular the choice of the destination country, appears to be motivated by similar factors as economic migration, even though probably to a different extent.

This reinforces the authors' call for better coordination and for a harmonization of refugee policy within the EU. In fact, the coordination problem is probably even broader and more complex than indicated by their paper, given the cross-county differences in asylum policies across many dimensions. These include border protection and enforcement of visa requirements, the efficiency of application processing, the generosity of conceding full or subsidiary refugee status, dispersion policies restricting the freedom about residential choice as well as access to the labour market and the welfare state.

These differences make it hard to even think about an 'optimal' policy. Moreover, at the heart of the problem is a complicated political economy game between the Member States, with potentially many trade-offs that involve humanitarian concerns, efficiency concerns, signalling, as well as power politics that are addressed by policies such as the 


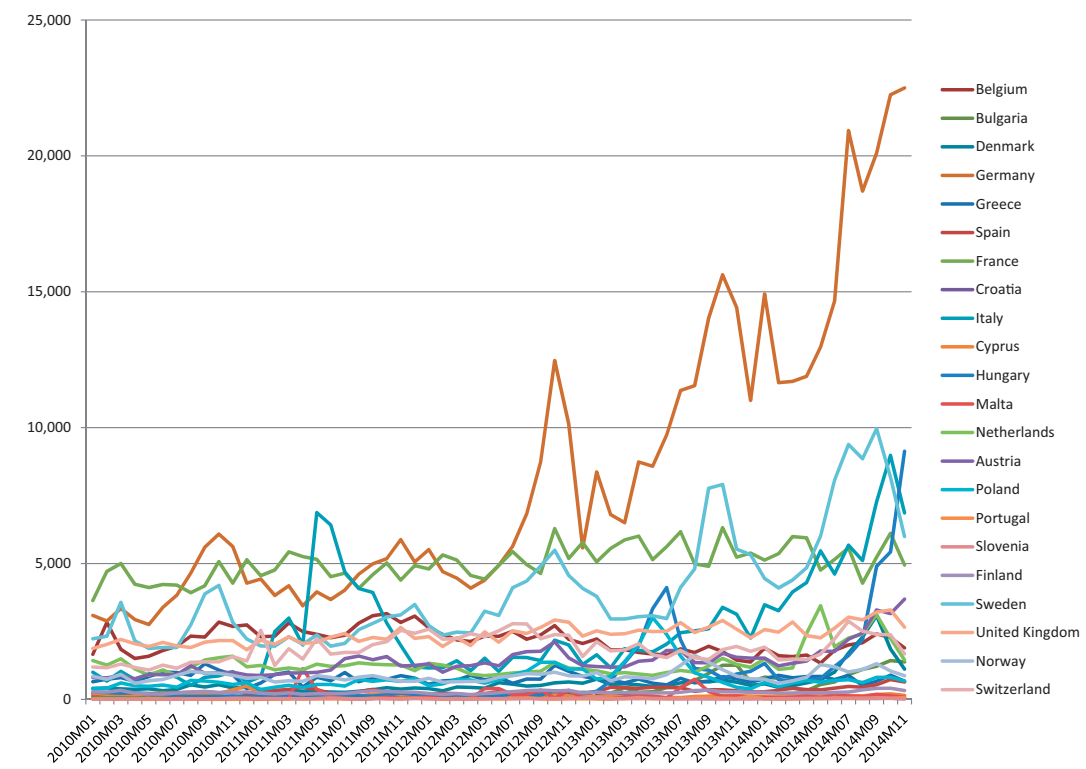

Figure 13. Asylum Applicants (rounded)

Source: Eurostat.

speed of administrative processes or the generosity of admission policy. The suggestion to implement a two-stage policy with decisions about asylum claims at the outer borders and with a transfer and quota system might help mitigating many of these strategic incentives.

Ultimately, the key question for dealing with refugee migration appears that of integration. With a subsidiary refugee status that might last years and with non-refoulement kicking in after the asylum application is rejected, while a voluntary return is possible at any stage, the refugees' incentives for integration appear complicated. Fast and transparent decisions are probably a way to provide those refugees with clear incentives who consider permanent residence. Yet, the status quo seems not to take this into account, in particular given the need to clear the fallout of the first months of the refugee crisis. Moreover, the evidence shown by the authors suggests that integration might be a very long and time-consuming process. Nevertheless, the status quo with its uncoordinated national policies and the associated economic and political costs appears unsustainable. Whether the proposed solution of securing EU outer borders, dealing with application before refugees even enter EU, and coordinated asylum policies with a matching-based allocation of refugees across host countries provides a feasible scenario will have to be seen in the future. In any case, the authors provide a sober and evidence-based contribution to the debate that is urgently needed and will serve as important and useful reference for future discussions of these issues. 


\section{Antonella Trigari}

Bocconi University

\section{What does this paper do?}

This paper provides a wide-ranging analysis of refugee migration, with emphasis on the recent refugee crisis. The paper first reviews the institutional framework regulating asylum policies and elaborates on how European countries interpret and put into practice these regulations. Second, it describes the key features of the current refugee crisis, mainly in terms of the distributions by routes of entry, country of origin and country of destination. Next, the paper compares the labour market outcomes of economic migrants and refugees by estimating the gap in their employment probabilities (using past refugee waves). Finally, it discusses the economics of refugee migration focusing on the economic and political trade-offs of asylum policies and emphasizing the benefits from coordination among European countries.

To succeed in these heterogeneous tasks, the authors make use of several sources of data: the UNHCR Population Statistics, Frontex Data, the European Union Labor Force Survey (EULFS) and the German Ministry for Immigration and Refugees Survey.

\section{Background}

Definition of a refugee. The paper clarifies the definition of a refugee. The GCR 1951, defines a refugee as 'a person who owing to a well-founded fear of being persecuted for reasons of race, religion, nationality, membership of a particular social group or political opinion, is outside the country of his nationality and is unable or, owing to such fear, is unwilling to avail himself of the protection of that country'. This definition emphasizes the presence of a threat for an individual person (i.e. an individual persecution) as the reason for granting the refugee status. In most cases, individual persecution is thus the basis of a permanent refugee status. To address general threats, the UNHCR considers as refugees all persons fleeing civil wars and ethnic, tribal and religious violence and whose country is unable/unwilling to protect them. In this case, the underlying threat is general, rather than individual, and it often leads to alternative forms of temporary humanitarian protection. In other words, individuals are considered refugees without the need of an individual status determination, but permanent asylum is not guaranteed.

Two refugee crises. To put the current refugee crisis into perspective, the paper compares it to the early 1990s Balkan crisis. Here are the numbers. In 1992, at the peak of the Balkan crisis, 850,000 applications were submitted, of which 700,000 in Europe. Refugees came mostly from the Balkans, Afghanistan, Iraq, Rwanda and Somalia. The 
stock of refugees reached its first peak in 1992, with almost 15 million refugees worldwide. In 2015, at the peak of the current crisis, over 2 million applications were presented, with 1.5 million in Europe. The refugees originated mostly from Syria, Afghanistan, Iraq and North Africa. In 2015, the stock of refugees reached its second and highest peak, with more than 15 million refugees worldwide.

The case of Syrians. The case of Syrians, in particular, illustrates the nature and extent of the current crisis. Before the conflict, the population of Syria was 22 million. In December 2015, almost 12 million people were classified as displaced (i.e. had to move away from their home). Out of those 12 million, about 6.6 million were internally displaced (stayed in Syria) and 5 million autonomously reached a third country. In this latter group, only 500,000 were granted asylum (or were waiting for it) in the EU, while 4.5 million were under a refugee-like status in a neighbour country to Syria. Finally, only 180,000 people were offered resettlement to a safe host country.

\section{What does the paper find? And what is my reading of the paper's story?}

There are four key messages delivered by this paper. First, there exists large heterogeneity in recent refugee policies across Europe. Countries differ substantially in efficiency (e.g. the processing rate is $37 \%$ in Greece, $73 \%$ in UK), generosity (the recognition rate is $2 \%$ in Greece, $18 \%$ in Denmark), type of status granted to a successful applicant (18\% full GCR status in Italy, $91 \%$ in UK), list of 'safe countries of origin' (0 in Norway, 26 in UK), labour market access (1 month waiting period in Portugal, 1 year in UK), health care access (unrestricted only in Italy, Belgium, Ireland). Second, the current refugee crisis led to a massive hike in illegal crossing and asylum applications. Illegal crossing increased 17-fold from 2009 to 2015 mostly via Central Mediterranean, Eastern Mediterranean and Western Balkan entry routes and mainly from Syria (38\%) and Afghanistan (20\%). Asylum applications increased five-fold over the same period mainly from Syria (17\%) and Afghanistan (10\%) and mostly to Germany, Sweden, Italy and Hungary. Third, refugees experience a delayed labour market integration relative to economic migrants. Refugees are about $10 \%$ less likely to be employed than economic migrants and the gap disappears only after 1520 years. Finally, the paper offers a way to optimal policy by attempting a cost and benefit analysis along a number of dimensions: permanent versus temporary status; urban versus rural location; and dispersed versus concentrated location. The policy prescription is coordination among receiving countries with a market for trading quotas in order to minimize total costs of granting asylum to a given number of refugees.

How do these findings come together to provide a coherent story? Here is my reading. First, the existing regulatory framework is unsuitable to handle the European crisis for two reasons: it leaves much room for host country interpretation and does not envisage a mechanism to spread the refugee burden. At the same time, the current refugee burden 
is unprecedented and unequally distributed. For this reason, countries implement heterogeneous policies, in large part to deter applications. For example, they delay labour market access after arrival or allow uncertainty about application outcome and permanence. These policies, in turn, cause lasting adverse effects on refugee employment outcomes by discouraging investment in host-specific human capital. Thus, coordination in asylum policies would reduce the free-rider problem, alleviate countries' distorted incentives and mitigate the adverse consequences on refugees' economic integration.

\section{Comments}

Let me now provide some more specific comments on the details of the analysis.

Heterogeneous policies: applications received versus efficiency. In Figure 4, the authors show that there is no correlation between efficiency, as measured by the processing rate of applications, and the number of applications received (normalized per 10,000 population). Based on this finding, the authors resolve that a country's processing rate can be thought of as a choice variable, potentially used to influence the application inflow. The figure, however, raises questions about the generality of the result. In fact, alternative normalizations or the use of absolute numbers may reveal some negative correlation. For example, normalizing by GDP would capture the effective refugee burden: Norway has small population but high GDP per capita and so would be closer to the left on the figure, while Spain would move to the right. Also, the use of absolute numbers might be more appropriate, as they would capture quasi-fixed costs of processing applications. If these alternative analyses indeed imply a negative correlation, then the authors' interpretation of efficiency as a choice variable would not be justified.

Heterogeneous policies: efficiency versus generosity. Figure 5 documents a positive correlation between efficiency (processing rate) and generosity (recognition rate) across countries. Based on this evidence, the authors argue that countries are not faster simply by rejecting more applications. This in turn suggests that countries may be choosing two dimensions to influence the application flow generosity and efficiency. However, the positive correlation may also suggest that some countries are faster simply because they are more generous. Moreover, selection may explain differences in recognition rates. For example, it might be the case that only richer and more educated people reach countries farther away from border crossing points the UK and Northern Europe. These people are better equipped to submit a successful application, inducing a positive correlation between generosity (they are more likely to be eligible) and efficiency (they are more likely to put together a complete and in order application). To address this issue, the authors could control for distance to border crossing points and/or perform robustness checks by dropping the UK, Denmark and Greece. 
Labour market integration: employment gaps. To analyse labour market integration of refugees, the authors use the 2008 wave of the EULFS, which covers past refugee waves. The main finding is that there is a $10 \%$ employment gap between refugees and economic migrants and that this gap decreases with the length of stay. The authors explain these results by arguing that refugees are conceptually very different from economic immigrants. The idea is that of a 'forced marriage' versus a 'chosen match': economic immigrants chose a country where to migrate while refugees did not have much of a choice. Also, refugees have lower incentives to invest in human capital, with lasting but fading effects on employment outcomes.

These results raise some concerns. First, Figure 11 shows that the refugee immigrant gap might be driven by the UK and Ireland the gap is much larger in these two countries compared to the rest with about $40 \%$ in Ireland, $20 \%$ in UK and almost $0 \%$ in other countries. The revised version of the paper shows in the Appendix that the estimates are robust to dropping the UK and/or Ireland.

Another interesting insight from Figure 11 is that the immigrant native employment gap is smaller in Ireland and the UK than in most other countries. It suggests that economic migrants may be positively selected in certain destinations. It is hard to become an economic migrant (obtain a working visa) in Ireland and the UK, especially from outside the EU. It would then be interesting to control for the strictness of immigration rules in the host country by area of origin.

An important question is why the refugee-native employment gap is much higher in the UK and Ireland than in other countries. For example, differences in the quality of education between origin and host country may be higher for the UK and Ireland than for other host countries. Or, as Borjas and Monras (2017) argue, refugee shocks adversely affect labour market opportunities of competing natives, and often have a favourable impact on complementary workers. In the UK and Ireland, refugees are more likely to be complementary to the native working population, hence the higher employment rate for natives. In southern countries, instead, refugees are more likely to be substitutes, hence the lower employment rate for natives. The authors could control for the number of refugees in the host country and for the joint distribution of skills/sectors of natives and refugees.

Decreasing employment gap: cohort effects. Figure 10 documents that the employment gap is decreasing in the duration of the stay. A key question is whether this happens because of a duration effect (integration into the receiving country) or a cohort effect (composition of refugees). Also, the gap in 2008 (the year of the survey) is smaller at 15 years since arrival. This finding could, however, be driven by the Balkan refugees from the early 1990s, who are closer in culture and education, and so easier to integrate. Data on more cross-sections seems key to address these issues.

In general, it would be desirable to include more controls in the analysis. For example, finer education levels, experience, wealth, income, etc. Also, the interaction of 
education with the country of origin seems important since the quality of education may vary significantly across countries, leading to skill downgrading. Moreover, it would be useful to control for policies in the host country, such as labour market access or share of refugees with full GCR status.

Policy trade-offs. The paper emphasizes several important policy trade-offs. The first relates to granting permanent or temporary status. Permanent status incentivizes investment in human capital, but has political costs and thus creates a free-rider problem. One concern with the analysis is that the preferences of refugees are not mentioned. Refugees, in fact, may want to return to their origin country, as it happened in the Balkan case. A permanent refugee status would not be needed in this case.

A second trade-off concerns the geographical allocation of refugees. Should it be in urban or rural areas? Should refugees be concentrated or dispersed? There are lower hosting costs in rural areas, for example, due to housing, but higher political costs. Refugees, in fact, lead to increasing support for right-wing anti-immigration parties in rural areas but not urban ones. Concentration helps integration into the labour market, due to contacts and network, but leads to unequally distributed costs within the country. At the same time, a number of non-monetary costs of concentration are not mentioned in the paper: lower incentives to learn the local language and culture, the rise of 'ghettos', such as Molenbeek in Brussels, the fact that ethnic segregation lowers government quality (Alesina and Zhuravskaya, 2011).

\section{One concluding remark}

The paper emphasizes differences between the current and the 1990s refugee crises: the concomitance of the current crisis with the aftershocks of a deep recession; the higher uncertainty about the resolution of the causes generating the flows; the larger magnitudes and the cultural differences of refugees. It then convincingly argues that these differences lead to greater political costs. But the paper offers no formal analysis of these political costs, focusing instead on the economic costs associated with labour market integration. Political economy's analyses of refugee migration should be high on the agenda!

\section{Panel discussion}

George Borjas emphasized that the paper does not examine the role of refugee agencies which, as intermediaries, have their own agenda and thus may not necessarily act in the best interests of refugees. He indicated that there are three different parties in the process (i.e. refugees, receiving countries and refugee agencies) and ignoring the latter may give a misleading picture of the issue. Sam Langfield asked to what extent a coordinated policy that secures Europe's outer borders and deals with asylum claims before refugees 
have crossed the border can be achieved with the agreement recently signed between Turkey and EU governments.

Timothy Hatton argued that the lack of coordination of policies across Europe is the main problem. Refugee hosting is a public good due to the humanitarian satisfaction everyone experiences if a refugee crisis is solved in a satisfactory way. Thus, there is need for a social planner and harmonization of policies. In a related point, Andrea Ichino wondered if the lack of coordination is a problem specific to the refugee crisis or a more general problem of European institutions. Kevin O'Rourke asked if the authors can obtain data on employment experiences of people that have been granted permanent versus temporary refugee status. Moreover, he pointed out that right now the refugees who make it into Europe are a selected sample, for example, likely richer and younger than the average citizen in the home country. If the asylum granting process is located in a third country outside the EU instead, this selection will likely change. Richard Portes questioned whether the number of refugees in recent years is higher in terms of total population (from both the receiving and sending countries) from what we have observed in the past, prior to World War II.

Replying to comments, Christian Dustmann first highlighted that despite the complexity and importance of refugee migration both politically and economically, the data available so far is simply insufficient to draw strong policy conclusions. He also clarified that refugee agencies are not as prevalent in Europe as they are in the United States, and argued that the agreement between Turkey and the EU was more an emergency measure. Regarding the lack of coordination in Europe, he agreed that EU institutions need to be adjusted but stressed the fact that this and other issues are being dealt with and that these institutions are being improved in the process. This ultimately represents strength of the EU rather than a weakness.

\section{DATA APPENDIX}

\section{A.1 ASYLUM APPLICATIONS AND REFUGEE STATUS RECOGNITIONS}

The annual information on UNHCR's population of concern and asylum application processing are taken from the UNHCR Statistical Online Population Database, which classifies persons of concern as follows: (1) refugees, individuals recognized under the 1951 Convention relating to the Status of Refugees, its 1967 Protocol, and/or the 1969 OAU Convention Governing the Specific Aspects of Refugee Problems in Africa; individuals recognized in accordance with the UNHCR Statute; individuals granted complementary forms of protection or enjoying temporary protection; and, since 2007, individuals in a refugee-like situation; (2) asylum seekers, individuals who have sought international protection and whose claims for refugee status have not yet been determined; (3) returned refugees, former refugees who have returned to their country of origin but are yet to be fully integrated; (4) IDPs, individuals who have been forced to leave their homes or places of habitual residence as a result of, or to avoid the effects of, armed conflict, and who have not crossed an international border; (5) returned IDPs, IDPs who were beneficiaries of 
UNHCR's protection and assistance activities and who returned to their areas of origin or habitual residence during the year; (6) stateless persons; (7) other individuals of concern, those who do not fall directly into any of the previous groups but to whom UNHCR extends its protection and/or assistance services. The data on asylum application processing include the numbers of applications submitted, pending applications at the beginning and end of the year, applications recognized, applications rejected and applications otherwise closed. Data are reported bilaterally for all world countries. As of the time of writing, the data, which are available on line, had been updated on 31 December 2014.

UNHCR also provides a monthly data set of asylum applications lodged in 38 European and 6 non-European countries between 1999 and 2015. Where possible, our figures exclude repeat/re-opened asylum applications and applications lodged on appeal or with courts.

\section{A.2 ILLEGAL CROSSINGS}

Quarterly data on illegal entries by route and origin country for each quarter from Q1 2009 to Q42015 were obtained from Frontex, the European Agency for the Management of Operational Cooperation at the External Borders of the Member States of the EU, which began gathering such information in 2009. Frontex defines illegal crossings as 'the number of third-country nationals detected by Member State authorities when entering or attempting to enter illegally the territory between border crossing points at external borders'. The recorded number of illegal crossings may differ from the actual flows of undocumented immigrants for at least two reasons: first, not all illegal crossings are detected, meaning that detected crossings are a lower bound for actual unauthorized crossings. Illegal crossings are determined by the combination of the number of people who attempt an illegal entry and the level of enforcement. Any variation in the number of detected crossings, therefore, can be due to variations both in the underlying flow of people and in the border enforcement intensity. This complicates comparisons over time and across routes of recorded crossings. A second issue is that multiple entry attempts by the same migrant are re-counted, leading to an over-estimation of the number of individuals attempting to cross the border illegally. Nonetheless, in the absence of reliable information on the size of these two effects, detected illegal crossings are the best available proxy for undocumented migratory pressure.

The data set distinguishes between the following nine routes: the Central Mediterranean route, the circular route from Albania to Greece, the eastern border route, the Eastern Mediterranean routes (sea and land), the West African route, the Western Mediterranean routes (sea and land) and the Western Balkan route.

\section{A.3 LABOUR MARKET OUTCOMES OF REFUGEE AND ECONOMIC MIGRANTS}

Our analysis is based on the 2008 wave of the EULFS, which is conducted in the 27 Member States of the EU and two countries of the European Free Trade Association 
(EFTA). It is a large quarterly household sample survey of people aged 15 and over, as well as of persons outside the labour force. The National Statistical Institute of each member country is responsible for selecting the sample, preparing the questionnaires, conducting the direct interviews among households and forwarding the results to Eurostat in accordance with the common coding scheme.

In certain countries, the 2008 survey included an ad hoc module that asked for information on reason for migration, thereby allowing us to identify refugees versus other (eco nomic) migrants. We, therefore, focus our analysis on the countries in which this ad hoc module was administered: Austria, Belgium, Cyprus, Germany, Spain, France, Greece, Ireland, Italy, Netherland, Norway, Portugal, Sweden and the UK. The reason-formigration question was asked to all non-native individuals who arrived in the country of residence when they were over 16 years of age. ${ }^{37}$ The 2008 interviewees were asked to choose among 8 options: (1) employment, intra-corporate transfer; (2) employment, job found before migrating; (3) employment, no job found before migrating; (4) study; (5) international protection; (6) accompanying family/family reunification; (7) family formation and (8) other. We assign the label refugee to all those who selected option (5), international protection, and the label economic migrant to all those choosing any of the other reasons. The sample for our empirical analysis includes individuals of working age (between 25 and 64 years old), not in full-time education or military service. After dropping all observations with missing data on education, reason for migration, or area of origin, we have an estimation sample of 476,518 individuals, of whom 440,594 are natives, 33,370 are economic immigrants and 2,554 are refugees.

\section{APPENDIX TABLES}

\section{REFERENCES}

37 Non native individuals (immigrants and refugees) are defined as 'foreign born' in all countries except Germany where they are defined as 'foreign nationals'. 
Adda, J., C. Dustmann and S. Gorlach (2016). 'The dynamics of return migration, human capi tal accumulation, and wage assimilation', Mimeo, UCL.

Table A1. Refugee-native and immigrant-native employment rate differentials

\begin{tabular}{|c|c|c|c|c|c|c|}
\hline & (1) & (2) & (3) & (4) & (5) & (6) \\
\hline Immigrant & $\begin{array}{l}0.059 * * * \\
(0.004)\end{array}$ & $\begin{array}{l}0.085^{\text {**** }} \\
(0.004)\end{array}$ & $\begin{array}{l}0.070 * * * \\
(0.004)\end{array}$ & & & \\
\hline Refugee & $\begin{array}{l}0.161^{\text {**** }} \\
(0.017)\end{array}$ & $\begin{array}{l}0.216^{* * * *} \\
(0.017)\end{array}$ & $\begin{array}{l}0.183^{* * * *} \\
(0.016)\end{array}$ & $\begin{array}{l}0.161^{\text {**** }} \\
(0.017)\end{array}$ & $\begin{array}{l}0.215^{* * * *} \\
(0.017)\end{array}$ & $\begin{array}{l}0.183 * * * \\
(0.016)\end{array}$ \\
\hline Immigrant EU15 & & & & $\begin{array}{l}0.032^{* * * *} \\
(0.007)\end{array}$ & $\begin{array}{l}0.041^{* * *} \\
(0.006)\end{array}$ & $\begin{array}{l}0.043^{* * *} \\
(0.006)\end{array}$ \\
\hline Immigrant nonEU15 & & & & $\begin{array}{l}0.072^{\text {**** }} \\
(0.005)\end{array}$ & $\begin{array}{l}0.105^{* * *} \\
(0.005)\end{array}$ & $\begin{array}{l}0.082^{* * * *} \\
(0.005)\end{array}$ \\
\hline Gender and age & & $\mathrm{X}$ & $\mathrm{X}$ & & $\mathrm{X}$ & $\mathrm{X}$ \\
\hline Education & & & $\mathrm{X}$ & & & $\mathrm{X}$ \\
\hline Observations & 476,518 & 476,518 & 476,518 & 476,518 & 476,518 & 476,518 \\
\hline$R^{2}$ & 0.02 & 0.18 & 0.22 & 0.02 & 0.18 & 0.22 \\
\hline
\end{tabular}

Notes: The table reports differences in employment probabilities between economic migrants/refugee migrants relative to natives (columns 13 ) and between EU15 migrants/non EU15 migrants/refugee migrants relative to natives (columns 4 6) estimated from linear probability models. The sample includes all individuals aged between 25 and 64, not in education or military service. All regressions include host country fixed effects. Gender: dum mies for male. Age: dummies for five year age groups. Education: dummies for lower secondary and tertiary edu cation. Robust standard errors in brackets.

$* * * p<0.01, * * p<0.05, * p<0.1$.

Source: Own calculations based on EULFS 2008.

Table A2. Employment rate differentials by area of origin

\begin{tabular}{|c|c|c|c|c|c|}
\hline & $\begin{array}{c}\text { NMS } 12 \\
\text { (1) }\end{array}$ & $\begin{array}{c}\text { Other } \\
\text { Europe } \\
(2)\end{array}$ & $\begin{array}{c}\text { Other } \\
\text { Africa } \\
(3)\end{array}$ & $\begin{array}{c}\text { South \& } \\
\text { East Asia } \\
\text { (4) }\end{array}$ & $\begin{array}{l}\text { N.Africa \& } \\
\text { Middle East } \\
\text { (5) }\end{array}$ \\
\hline \multirow[t]{2}{*}{ Immigrant } & $0.031 * * *$ & $0.083^{* * *}$ & $0.034 * * *$ & $0.101 * * *$ & $0.182^{* * *}$ \\
\hline & $(0.009)$ & $(0.009)$ & $(0.011)$ & $(0.011)$ & $(0.010)$ \\
\hline \multirow[t]{2}{*}{ Refugee } & 0.056 & $0.083^{* * *}$ & $0.224^{* * * *}$ & $0.234 * * *$ & $0.325 * * *$ \\
\hline & $(0.056)$ & $(0.027)$ & $(0.036)$ & $(0.041)$ & $(0.033)$ \\
\hline Observations & 445,719 & 447,643 & 443,300 & 444,664 & 445,365 \\
\hline$R^{2}$ & 0.23 & 0.23 & 0.23 & 0.23 & 0.23 \\
\hline$F$ test (Imm. versus Ref.) & 0.21 & 0.00 & 25.03 & 9.96 & 17.45 \\
\hline Prob $>F$ & 0.65 & 0.99 & 0.00 & 0.00 & 0.00 \\
\hline
\end{tabular}

Notes: The table reports differences in employment probabilities between economic migrants/refugee migrants relative to natives estimated separately (through linear probability models) for different areas of origin. The sam ple includes all individuals aged between 25 and 64, not in education or military service. Economic migrants from EU15 countries are excluded. All regressions control for gender, age (dummy variables for 5 year age groups), education (dummy variables for lower secondary and tertiary education) and host country fixed effects. Tests for the equality of coefficients for economic vs refugee migrants are reported. Robust standard errors in brackets.

$* * * p<0.01, * * p<0.05, * p<0.1$.

Source: Own calculations based on EULFS 2008. 


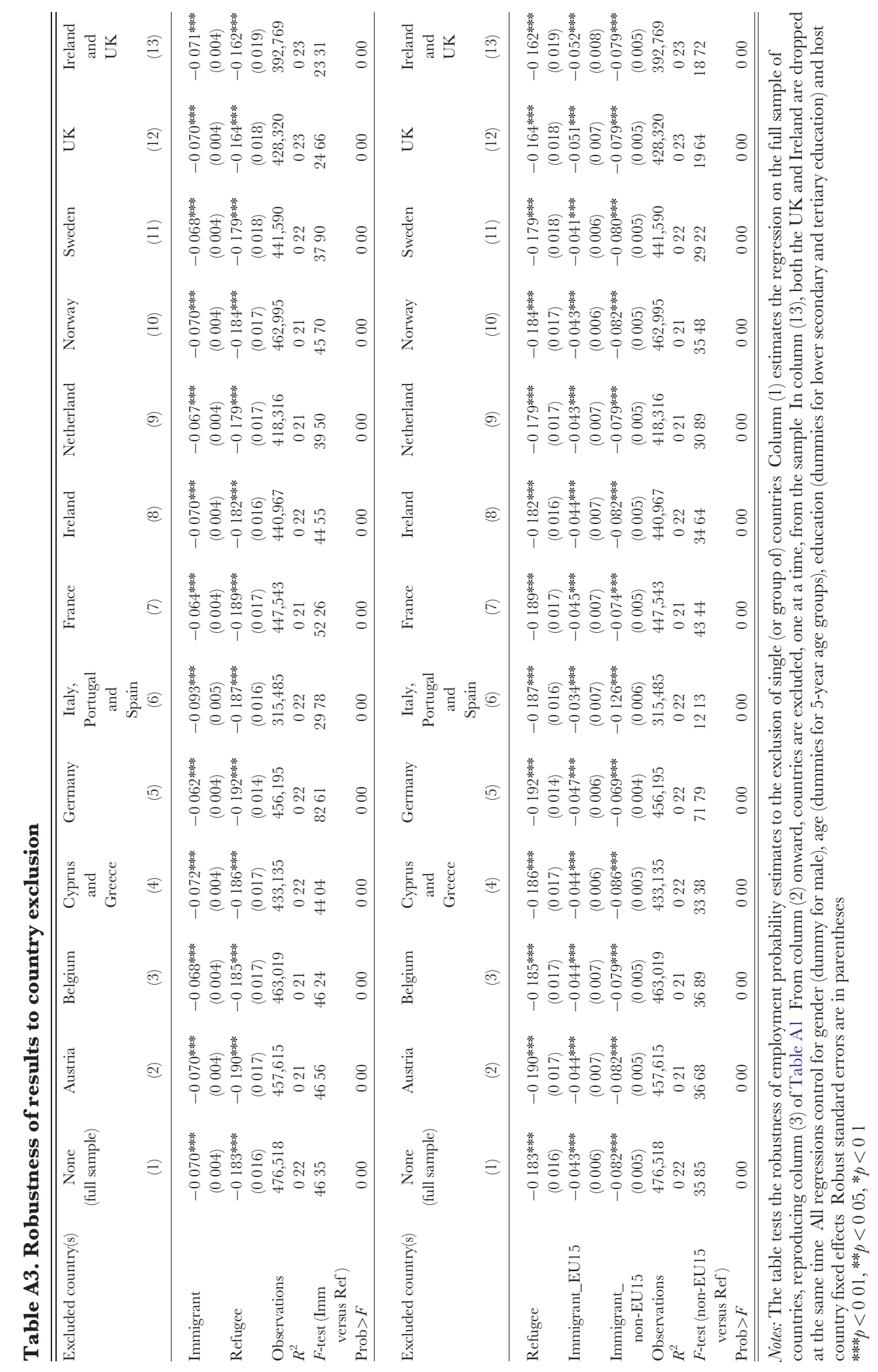


Aiyar, S., B. Barkbu, N. Batini, H. Berger, E. Detragiache, A. Dizioli, C. Ebeke, H. Lin, L. Kaltani, S. Sosa and A. Spilimbergo (2016). 'The Refugee Surge in Europe: Economic Challenges' IMF Discussion Note No.16/02.

Alesina, A. and E. Zhuravskaya (2011). 'Segregation and the quality of government in a cross section of countries', American Economic Review, 101, 18721911.

Bell, B., F. Fasani and S. Machin (2013). 'Crime and immigration: evidence from large immi grant waves', The Review of Economics and Statistics, 21, 127890.

Ben Porath, Y. (1967). 'The production of human capital and the life cycle of earnings', fournal of Political Economy, 75, 35265.

Bevelander, P. and R. Pendakur. (2014). 'The labor market integration of refugee and family re union immigrants: a comparison of outcomes in Canada and Sweden', Fournal of Ethnic and Migration Studies, 40, 689709.

Bratsberg, B., O. Raaum and K. Røed (2014). 'Immigrants, labour market performance and so cial insurance', Economic Fournal, 124, F644 83.

Dustmann, C. (2016). 'Labor market integration of refugees in Norway', Mimeo, Mimeo Frisch Centre.

Canning, D., S. Raja and A.S. Yazbeck (eds.), (2015). Africa's Demographic Transition: Dividend or Disaster?. Africa Development Forum; World Bank; and Agence Française de Développement, Washington, DC.

Cortes, K.E. (2004). 'Are refugees different from economic immigrants? Some empirical evi dence on the heterogeneity of immigrant groups in the United States', The Review of Economics and Statistics, 86, 46580.

Couttenier, M., V. Preotu, D. Rohner and M. Thoenig (2016). 'The violent legacy of victimiza tion: post conflict evidence on asylum seekers, crimes and public policy in Switzerland', Centre for Economic Policy Research Discussion Papers 11079.

Damm, A.P. (2009). 'Ethnic enclaves and immigrant labor market outcomes: quasi experimental evidence', Fournal of Labor Economics, 27, 281314.

Dustmann, C. (1993). 'Earnings adjustment of temporary migrants', Fournal of Population Economics, 6, 15368.

. (1999). 'Temporary migration, human capital and language fluency of migrants', Scandinavian Fournal of Economics, 101, 297314.

. (2000) 'Temporary migration and economic assimilation', Swedish Economic Policy Review, 7, 21344.

Dustmann, C., K. Vasiljeva and A.P. Damm (2016). 'Refugee migration and electoral out comes', CReAM DP 19/16.

Dustmann, C. and U. Schonberg (2012). 'What makes firm based vocational training schemes successful? The role of commitment', American Economic fournal Applied, 4, 3661.

Edin, P., P. Fredriksson and O. Assund (2003). 'Ethnic enclaves and the economic success of immigrants evidence from a natural experiment', The Quarterly fournal of Economics, 118, 32957.

Facchini, G., O. Lorz and G. Willmann (2006). 'Asylum seekers in Europe: the warm glow of a hot potato', Fournal of Population Economics, 19, 41130.

Fernández Huertas Moraga, J. and H. Rapoport (2015a). 'Tradable refugee admission quotas and EU asylum policy', CESifo Economic Studies, 61, 63872.

- (2015b). 'Tradable refugee admission quotas (TRAQs), the Syrian crisis and the new European agenda on migration', IZA Journal of European Labor Studies, 4,

Hainmueller, J., D. Hangartner and D. Lawrence (2016). 'When lives are put on hold: Lengthy asylum processes decrease employment among refugees', Science Advances, 2, 17.

Hatton, T.J. (2004). 'Seeking asylum in Europe', Economic Policy, 38, 562.

. (2009). 'The rise and fall of asylum: what happened and why?', Economic Fournal, 119, 183213.

. (2015). 'Asylum policy in the EU: the case for deeper integration', CESifo Economic Studies, $61,60537$.

. (2016). 'Refugees, asylum seekers and policy in OECD countries', American Economic Review Papers and Proceedings, 106, 4415.

Hatton, T.J. and J.G. Williamson (2006). 'Refugees, asylum seekers and policy in Europe', in F. Foders and R.F. Langhammer (eds.), Labour Mobility and the World Economy, Springer, Kiel. 
Hornung, H. (2014). 'Immigration and the diffusion of technology: the huguenot diaspora in Prussia', American Economic Reviewe, 104, 84122.

Luik, M.A., H. Emilsson and P. Bevelander (2016). 'Explaining the male native immigrant em ployment gap in Sweden: the role of human capital and migrant categories', IZA Institute of Labor Economics DP No. 9943.

Moser, P., A. Voena and F. Waldinger (2014). 'German Jewish emigrés and U.S. invention', American Economic Review, 104, 322255.

Ruhl, S. and H.W. Lederer (2001). Migrationsbericht 2001 der Ausländerbeauftragten im Auftrag der Bundesregierung. Beauftragte der Bundesregierung fur Ausländerfragen (ed.), Berlin.

Ruhl, S., M. Neske and E. Currle (2004). Migrationsbericht der Beauftragten der Bundesregierung für Migration, Flüchtlinge und Integration im Auftrag der Bundesregierung (Migrationsbericht 2003). Beauftragte der Bundesregierung fur Migration, Fluchtlinge und Integration im Auftrag der Bundesregierung (ed.), Berlin.

UNHCR (2000). The State of the World's Refugees, Fifty Year of Humanitarian Action, Chapter 9, Oxford University Press, Oxford.

(2015a). Statistical Tearbook 2014, UNHCR, Geneva.

(2015b). UNHCR Refugee Resettlement Trends 2015, UNHCR, Geneva.

Worbs, S. and E. Bund (2016). Qualifikationsstruktur, Arbeitsmarktbeteiligung und Zukunftsorientierungen. BAMF Kurzanalyse, German Ministry for Migration and Refugees (Bundesamt fur Migration und Fluchtlinge), Berlin. 